\title{
Las cien obras clave del repertorio bibliográfico español de la educación física y el deporte en su proceso de legitimación e institucionalización (1807-1938)
}

\author{
Xavier TORREBADELLA FLIX \\ Universidad Autónoma de Barcelona \\ Facultad de Ciencias de la Educación \\ xtorreba@gmail.com \\ Javier OLIVERA BETRÁN \\ Instituto Nacional de Educación Física de Catalunya de Barcelona. \\ Director de la revista Apunts. Educación fisica y deportes (ISSN: 1577-4015) \\ jolivera@gencat.net
}

Recibido: Noviembre 2011

Aceptado: Julio 2012

Resumen: En este estudio se presenta una selección de las cien obras de referencia del repertorio bibliográfico de la educación física y el deporte que contribuyeron a legitimar e institucionalizar este ámbito académico, social y profesional en España entre 1807 y 1938. La selección ha venido marcada por una batería de seis criterios de relevancia en el campo de la educación física y el deporte: originalidad de contenidos y métodos, orientación y valor del objeto perseguido, trascendencia intelectual y profesional, impacto y alcance social, carácter ideológico dominante y rigor técnico y científico. A partir de estos criterios se presenta una clasificación cronológica, una ubicación temática de estas cien obras y una valoración de cada obra en relación al número de criterios que cumplen. Seguidamente, abordamos un análisis interpretativo sobre el valor referencial de estas cien obras clave respecto al legado bibliográfico de la educación física y el deporte en este período y sus contribuciones en los ocho campos temáticos distinguidos. Las distintas aportaciones de autores, desde posiciones diferentes y de diversos campos profesionales conformaron un legado bibliográfico sólido intelectualmente y al servicio de la población que impulsó el proceso histórico de legitimación social e institucional de la educación física y el deporte en España.

Palabras clave: bibliografía; repertorio bibliográfico; educación física; deporte; gimnástica

One hundred key books of bibliographic repertoire in the process of legitimization and institutionalization of physical education and sport in Spain between 1807 and 1938

Abstract: Throughout this study it will be presented a selection of reference hundred books
from the bibliographic repertoire of physical education and sport, which helped to legitimize
and institutionalize this academic, social and professional in Spain between 1807 and 1938 . The
selection has been marked by a battery of six criteria of relevance in the field of physical 
education and sport: originality of contents and methods, guidance and value of the objective, professional and intellectual significance, impact and social outreach, the dominant ideological and scientific rigor. Based on these criteria presents a chronological classification, a location a hundred themes of each book in relation to the number of criteria met. Next, we address an interpretive analysis of the reference value of these hundred key works of bibliographic legacy of physical education and sport in this period and their contributions in the eight thematic areas distinguished. The individual contributions of authors, from different positions and different professional fields formed and intellectually solid bibliographic legacy and service of the population that has driven to the historical process of social and institutional legitimization of physical education and sport in Spain.

Keywords: bibliography; bibliographic repertoire; physical education; sport; gymnastic.

\section{INTRODUCCIÓN}

Las disciplinas científicas requieren de repertorios bibliográficos para reconocer desde la perspectiva histórica su proceso evolutivo y su plena validación académica e intelectual. La educación física y el deporte como ámbitos del conocimiento humano, que contiene saberes y praxis en íntima amalgama, y que pretende alcanzar la cientificidad también necesita un repertorio historiográfico. Mediante el estudio sistemático de las obras, las ediciones y los autores podemos conocer aspectos esenciales de nuestra historia específica relacionados con: el surgimiento de las primeras inquietudes, los distintos contextos históricos respecto a la edición de las obras, los objetivos y finalidades, los recursos utilizados, los autores y su procedencia social e intelectual, la estructura de las obras, los contenidos, las editoriales y las ediciones realizadas, los lectores a quienes va dirigida la obra, los éxitos editoriales y los fracasos, las mentalidades, los mensajes de las obras o las influencias.

El conocer y estudiar estas obras y sus respectivos autores es una tarea esencial de nuestra historia contemporánea, con el fin de justificar el rico proceso histórico que han protagonizado hasta el momento actual y reconocer el servicio prestado a nuestra sociedad durante este período en el ámbito de la educación, la recreación, la salud y la competencia deportiva.

La educación física tal como la reconocemos hoy hunde sus raíces en el movimiento filantrópico de fines del siglo XVIII, de hecho es la publicación de una obra en 1793 Gymnastik für die Jugend (Gimnasia para la Juventud), del profesor germánico de la escuela filantrópica de Schnepfental J. C. F. Guts Muths (1759-1839), la que se constituye como punto de partida editorial de la educación corporal como parte imprescindible de la educación integral del individuo. La representatividad y utilización de esta obra en el movimiento filantrópico de inspiración en las obras de J. J. Rousseau (1712-1778), su traducción a la gran mayoría de lenguas europeas y el número de ediciones que tuvo la convierten en una obra de referencia obligada en el nacimiento de la educación física en Europa. 
Fruto de la aportación de Rousseau, de la experiencia filantrópica y del pedagogo germano J. B. Basedow (1723-1790) y de las influencias del sistema pedagógico del suizo J. H. Pestalozzi (1746-1827) se configuran tres escuelas gimnásticas en el continente europeo: la sueca en el horizonte cultural nórdico, la germánica en el ámbito cultural centroeuropeo y la francesa en el área cultural francófona; que durante el siglo XIX desarrollaron distintos sistemas de de pedagogía corporal con pocas interferencias entres ellas y con diversas aportaciones originales de cada una.

El deporte surge de manera simultánea en los colegios de élite de Inglaterra (Public School) en el contexto de la revolución industrial y adoptando el espíritu de esa nueva época. Nace de la racionalización, reorganización, modernización e institucionalización de algunos juegos y competencias populares de épocas anteriores. En el último cuarto del siglo XIX, el deporte se expande fuera de las fronteras territoriales y culturales del mundo anglosajón y entra en contacto con los sistemas gimnásticos del momento, rivalizando en torno a la idoneidad educativa de cada uno de ellos.

En el contexto europeo surgen en España las primeras inquietudes e iniciativas por personas impregnadas del espíritu de la Ilustración y muy sensibles a las corrientes progresistas que venían del exterior. En este ambiente cultural y pedagógico, el coronel Francisco de Amorós y Ondeano funda el Real Instituto Militar Pestalozziano (1806-1808) en el que se formaron los infantes de la Corona española y en el que se impartían las primeras clases de educación corporal con los nuevos enfoques y tendencias. Con la invasión del país por las tropas napoleónicas y la consiguiente Guerra de la Independencia, el afrancesado Amorós se exilia a Francia y funda la Escuela Gimnástica Francesa. En 1830 publica en Paris su obra cumbre Manuel d'éducation physique, gymnastique et morale, el fundamento de su doctrina gimnástica, que paradójicamente nunca fue traducida al español.

En este ambiente se genera un rico y abundante repertorio de obras editadas en España en el que sorprenden los autores nacionales que escribieron sobre la gimnasia, la educación física o la pedagogía gimnástica lo que demuestra el interés por esta materia como regeneradora moral y física de la raza, robustecimiento de los cuerpos infantiles, preservar la salud de nuestros niños o fortalecer a nuestros soldados con una instrucción física para la guerra.

El deporte irrumpe en España en el último cuarto del siglo XIX y obtiene un éxito indudable que va acrecentándose conforme entra y avanza el siglo XX. En los años veinte, una vez superadas las barreras sociales y culturales de su origen social y procedencia territorial, el deporte pasó a ser una práctica mucho más popular y sugerente ya que estaba investido de modernidad y poseía el aura de lo nuevo, avanzado y prestigioso. El deporte se fue imponiendo al resto de sistemas corporales de carácter gimnástico y/o de educación física y poco a poco se convirtió en un espectáculo y en una praxis. Aunque la práctica mayoría de obras 
sobre el deporte se publican en el siglo pasado y corresponden básicamente a autores nacionales.

El conjunto de la producción bibliográfica de obras y autores de la educación física y el deporte en España durante el período decimonónico y primer tercio histórico del siglo XX (hasta el fin de la II República) fue determinante para su reconocimiento intelectual, académico, social, profesional e institucional. El presente estudio trata de conocer qué obras y autores tuvieron una notable influencia en el proceso de legitimación social e institucional de la educación física y el deporte en este período, las razones de su elección y cuáles fueron sus contribuciones específicas en los distintos campos disciplinares considerados.

Por tanto presentamos la selección de cien obras de referencia del repertorio bibliográfico de la educación física y el deporte que contribuyeron a legitimar e institucionalizar este ámbito académico, social y profesional en España entre 1807 y $1938^{1}$. La selección ha venido marcada por una serie de criterios de relevancia bibliográfica, impacto social y rigor intelectual en el campo de la educación física y el deporte en nuestro país. A partir de estos criterios se presenta una clasificación cronológica, una ubicación temática de estas cien obras y una valoración de cada obra.

\section{LA PRODUCCIÓN BIBLIOGRÁFICA COMO INSTRUMENTO CLAVE EN EL PROCESO DE LEGITIMACIÓN E INSTITUCIONALIZACIÓN DE LA EDUCACIÓN FÍSICA Y EL DEPORTE EN ESPAÑA}

A principios del siglo XIX, las Escuelas Gimnásticas y la Escuela deportiva inglesa configuraron cada una por separado un entramado ideológico crítico interno que duró todo el período decimonónico. Después se extendió entre todas las Escuelas con sus respectivas doctrinas triunfantes una "guerra de métodos" que se prolongó hasta la II Guerra Mundial y que supone uno de los debates más relevantes de la historia de la educación física y el deporte. Este entramado de sistemas y métodos, en el que los argumentos morales quedaron implícitos en la concepción de educación física y posteriormente en la de deporte, generó gran diversidad de posicionamientos y un notable confusionismo (Olivera y Olivera, 1994).

En esta coyuntura ideológica de métodos se produce paralelamente una creciente expansión de las doctrinas y movimientos por todo el territorio europeo que también llega a España. Desde principios del siglo XIX se gesta una literatura específica, con obras originales y autores genuinos, dirigida a promover y divulgar

\footnotetext{
${ }^{1}$ Olivera, Javier: "Prólogo". En Torrebadella, Xavier: Repertorio bibliográfico inédito de la educación fisica y el deporte en España (1800-1939). Madrid: Fundación Universitaria Española, 2011 b.
} 
las prácticas gimnásticas y deportivas en los diferentes ámbitos sociales, académicos, culturales y políticos en nuestro país. Todos los autores que se ocuparon de escribir en torno a la educación física y el deporte durante el período de 1800 a 1939 mostraron un interés común por legitimar la materia en el ámbito profesional y defenderla en el espacio educativo, político, científico, cultural y social. En conjunto persistió la entusiasta intención de promover una educación física que contribuyera a la noble causa de la regeneración física y moral.

Diversas tesis consultadas coinciden en situar a la educación física y al deporte en el contexto del regeneracionismo individual y colectivo con recargados argumentos a favor del patriotismo o la defensa nacional ${ }^{2}$. Hacia finales del siglo XIX, las voces del regeneracionismo reclamaron la salud, la fortaleza física del cuerpo robusto y ágil y la templanza espiritual y moral como antídoto a la depauperación física y a la degeneración moral de los ciudadanos. La educación física se ofreció como salvación y mejora de las condiciones higiénicas y sanitarias, como el curalotodo de las enfermedades, sobre todo de la tuberculosis el mal de la época-, y también como remedio de la debilidad física de la mujer. Se llegó incluso a la idea generalizada, que la educación física en la mujer debía ser el primer objeto de atención para lograr el anhelado regeneracionismo físico. Este discurso tomó especial protagonismo en el colectivo de profesionales de la enseñanza gimnástica que supo agruparse en asociaciones para defender sus intereses profesionales y propagandísticos (Pastor, 1997b). Este asociacionismo motivó intereses comunes en otros ámbitos profesionales que también tenían algo que decir en la urgente necesidad de atender los llamados problemas de la educación física. En este contexto la sociedad española permitió reproducir en su seno la emergente expansión que el fenómeno del sport-sistema de educación física anglosajón- acaecía en toda la Europa moderna, tanto en el entorno educativo como en el recreativo (Olivera, 1993)

El contenido de las obras nos muestran el desarrollo de la educación física -ya sea a través de la gimnástica o de las prácticas deportivas-, las evoluciones metodológicas, los ámbitos y campos de aplicación, las discusiones doctrinales, las influencias recibidas o los problemas del estatus profesional. En los tratados, manuales o libretos, se descubren numerosas influencias extranjeras, aunque también se comprueba cómo se funden éstas con las genuinas aportaciones de autores nacionales, aunque en la mayoría de ellos se puede apreciar una cierta "inopia pedagógica" o técnica por la falta de erudición y de conocimientos empíricos (Pastor, 2003).

Las obras de carácter teorizante y propagandístico se centraron en divulgar y convencer de la utilidad, del provecho y de la necesidad de desarrollar una educación

\footnotetext{
2 Incluso existieron algunas prácticas extrapoladas de otros países -batallones infantiles, Boy scouts y otras organizaciones juveniles y deportivas- que fueron presentadas como la solución a los problemas de regeneración física y moral del país.
} 
física sistemática. En este discurso los argumentos iníciales partieron de la recuperación de los clásicos. Hubo alusiones y citas a Homero, Hipócrates, Heródoto, Aristóteles, Platón, Píndaro, Juvenal, Pitágoras, Sófocles o Eurípides; en suma las aportaciones de los grandes pensadores clásicos avalaron el llamado "renacimiento de la educación fisica". A través de estos modelos, los autores modernos propugnaron el acercamiento al gimnasio, al campo de juego, a la palestra o al olimpismo y recuperaron el célebre aforismo "mens sana in corpore sano", que recurrentemente nunca faltó como cita clásica de la literatura clásica. La concepción hacia una educación integral también fue expresada a través de las voces que manifestaron la paridad entre la educación fisica, la educación intelectual y la educación moral. Así las influencias y el crédito de autores reconocidos mucho más cercanos en el tiempo como Locke, Kant, Rousseau, Montaigne, Rabelais, Basedow, Pestalozzi o Spencer también se mencionaron por muchos autores que deseaban el renacer físico, intelectual y moral de las nuevas generaciones.

Las manifestaciones más representativas del "renacimiento de la cultura fisica" en Europa se prodigaron en países como Alemania, Inglaterra, Suecia o Francia (Diem, 1966). Nuestros compatriotas - gimnasiarcas, pedagogos, higienistas o sportsmen- tomaron como referencia sus modelos y frecuentemente los antepusieron como horizontes de progreso.

Los principales autores tratados explicaron por todos los medios a su alcance en qué consistía la educación física, cuál era su verdadero sentido, sus medios, sus objetivos y su finalidad. Discutieron muchísimo por conocer qué sistema o método en el ámbito de la gimnástica y/o educación física era el mejor. Algunos fueron empíricos, otros se consideraron científicos. Otros más, meros aficionados, ejercieron la profesión y la defendieron incluso como predicadores. Los autores se preocuparon por disponer de los medios más oportunos para alcanzar los objetivos propuestos, reivindicando, denunciando e insistiendo con orgullo aquello que creían y pretendían. Los portavoces de la educación física fueron constantes en sus reivindicaciones y argumentos y se repitieron hasta la saciedad. Escribieron sus obras, las presentaron a concursos y algunas veces fueron premiadas, pero lamentablemente nunca fueron lo suficientemente valoradas por los círculos intelectuales, políticos e institucionales de la época. Muchos de los personajes fueron incomprendidos en sus quehaceres diarios del ejercicio de la profesión y tuvieron que "nadar contra corriente".

A principios del siglo XIX fue gestándose un movimiento gimnasiarca español, que aunque fue heterogéneo en el ámbito profesional e incluso en el doctrinario y científico, encontramos un nexo, una visión común, que prevaleció en cada uno de los representantes a lo largo de más de cien años: ilustrar al pueblo de la idea del regeneracionismo a través de la educación física.

Como movimiento científico e intelectual les faltó quizás unidad institucional, mayor reconocimiento oficial y más coherencia en la defensa de un doctrinario científico convergente al margen de las discusiones bizantinas de los métodos y 
sistemas de educación física. Como llegaron a citar algunos de ellos, la labor por lograr el verdadero renacimiento de la educación física significaba un "momento de luchas", en el que había que aunar múltiples esfuerzos (Sánchez, 1884: 55).

A finales del siglo XIX, el movimiento gimnasiarca deseaba el reconocimiento de su condición cómo profesores de Gimnástica por lo que se agrupó en asociaciones de intereses profesionales y propagandísticos mutuos. Este asociacionismo motivó intereses comunes de otros ámbitos profesionales pedagogos, higienistas, médicos y otros científicos, humanistas o políticos- que igualmente percibieron los problemas de la educación física.

En este contexto la sociedad española permitió reproducir en su seno la emergente expansión que el fenómeno del sport-sistema de educación física anglosajón- acaecía en toda la Europa moderna. La propaganda de la educación física también se llevó a las páginas de nuestra incipiente prensa deportiva, que coadyuvó al afán regeneracionista con la expansión de todo aquello que venía del extranjero (Olivera, 1993).

Las aportaciones editoriales de la bibliografía gimnástico-deportiva de la educación física se divulgaron en la prensa genérica, en las revistas de sociedad, en las publicaciones periódicas especializadas -de gimnástica y/o educación física- y en la prensa deportiva. Las noticias de libros, anuncios, recensiones y crónicas de los libros también fueron un valioso medio de propaganda para el conocimiento y adquisición de las obras editadas (Torrebadella, 2009).

De esta manera y a lo largo del período, la bibliografía gimnástico-deportiva de la educación física fue contribuyendo a legitimar el llamado proceso de institucionalización de la educación física y el deporte en España.

\section{MÉTODO, ORDENACIÓN Y CRITERIOS DE SELECCIÓN}

Nuestros trabajos precedentes han permitido fijar el estudio bio-bibliográfico y bibliométrico en torno a la literatura gimnástica y deportiva de la educación física (Torrebadella, 2000a, 2009 y 2011b). Ello nos ha permitido presentar esta selección de cien obras, que creemos representa el legado más importante y representativo de la bibliografía de la educación física y el deporte publicadas en España entre 1807 y 1938.

Asimismo deseamos expresar nuestra coincidencia con Pastor Pradillo (2005a y 2005b), cuando comprobamos la infravaloración de la educación física en el ámbito historicista de la pedagogía española y observamos la poca relevancia que adquiere la bibliografía propia de la época, para explicar la contribución de la materia a la fundamentación de la pedagogía general y a otros ámbitos como el higiénico-médico, el militar o el deportivo. Inclusive participamos de la idea que: "Hasta ahora, la bibliografía relacionada con los libros de educación fisica ha suscitado un escaso interés también en los investigadores de este género" (Pastor, 2005b: 11). 
Hemos elegido este período por tratarse del momento en que surgen los grandes movimientos gimnásticos de la educación física del siglo XIX. Además, durante este período se desarrollan los contenidos técnicos y doctrinales de la educación física y el deporte que se gestaron como fruto de los cambios sociales de la revolución industrial y las corrientes y ambientes ideológicos antes y después de la I Guerra Mundial; una influencia que ha llegado hasta nuestros días. El largo período del Franquismo desahució todo el legado histórico de la educación física y el deporte, desacreditando por olvido el testimonio de muchos autores y obras que quedaron silenciados. El objeto de estudio ha consistido en rescatar e identificar las obras editadas en este período y seleccionar entre ellas aquellas que creemos pueden ser más representantes del patrimonio histórico bibliográfico de la educación física y el deporte. Como anota Betancor y Vilanou (1895) "poner a disposición de los investigadores e historiadores todo un caudal e informaciones que se encuentran desperdigados por doquier" (p. 67).

El repertorio de estas cien obras que presentamos dispone de una ordenación cronológico-nominal. Para facilitar la comprensión bibliográfica se ha huido de las descripciones estandarizadas y academicistas, buscando mayor claridad y sencillez. Hemos precisado la descripción en "base simplificada", sirviéndonos como guía la normativa internacional ISBD (International Standard Bibliographic Description), redactada por la FIAB (Federación Internacional de Asociaciones de Bibliotecarios y Bibliotecas). Es por ello, que hemos descrito formalmente el asiento bibliográfico con el siguiente orden de elementos:

- Mención de responabilidad principal o autoridad [nombre completo del autor] ${ }^{3}$.

- Título completo de la obra (cursiva) y citaciones de portada.

- Responsabilidad física del documento: Mención de pie de imprenta y/o editorial, lugar de publicación y fecha.

- Descripción física: páginas, ilustraciones, láminas, gráficos, tamaño)

- Características a pie de página: ediciones conocidas y otras informaciones relevantes ${ }^{4}$.

- Ámbito general descriptivo al que va dirigida la obra ${ }^{5}$.

- Criterios contemplados de selección numérica de la obra.

${ }^{3}$ En la mención de la autoridad, lo incluido entre paréntesis no pertenece a la portada de la obra, sino que ha sido añadido por la investigación, con objeto de completar la información.

${ }^{4} \mathrm{Si}$ la edición se cita antes del punto final, quiere decir que esta información ha sido ofrecida en la misma obra. Si la edición se cita después del punto, quiere decir que ha sido incorporada por la investigación.

5 Ámbito pedagógico [AP] / Ámbito higiénico-Médico [AHM] / Ámbito Militar [AM] / Ámbito Científico-Técnico [ACT] / Ámbito divulgativo y propagandístico [ADP] / Ámbito Gimnástico Popular [AGP] / Ámbito Deportivo [AD] / Ámbito bibliográfico y documental [ABD] 
La selección ha sido fijada mediante la adopción de varios criterios preestablecidos como la originalidad, la orientación, la trascendencia, el impacto social, el carácter ideológico o la calidad de contenidos. A continuación se numeran los criterios contemplados, indicando en cada asiento bibliográfico los criterios cumplidos por su orden numérico:

1. La originalidad de la obra, en cuanto representa la exposición de contenidos inéditos.

2. La orientación de la obra dirigida a un ámbito singular relevante y del valor del objeto perseguido.

3. La trascendencia en los círculos intelectuales y profesionales.

4. El impacto social y popularidad de la obra por su alcance utilitario.

5. El carácter ideológico respecto a las obras que mejor representan una corriente de pensamiento concreta.

6. La calidad en contenidos de rigor científico, el peso doctrinal y la erudición del autor.

La selección de estas cien obras - 37 registros del siglo XIX y 63 del siglo XXpuede explicar en gran medida la evolución histórica de la educación física y el deporte en nuestro país desde 1800 hasta el final de la II República.

\section{CIEN OBRAS DE REFERENCIA EN LA EDUCACIÓN FÍSICA Y EL DEPORTE EN ESPAÑA (1807-1938)}

1807 AMAR DURIVER, P. M. A. et JAUFFRET, L. F.: La gimnástica o escuela de la juventud, tratado elemental de juegos, de exercicios considerados en razón de su utilidad fisica y moral. Adornada con 32 láminas. Traducida del francés ${ }^{6}$, Imp. de Álvarez, Madrid, 1807. 360 p.: 32 h. de lám. pleg.; 16 cm. [AP] 1, 2

1814 GONZÁLEZ, Félix: Educación Física del Hombre: Necesidad de promoverla en España por las madres y por las escuelas públicas de enseñanza. Discurso médico político escrito a la Regencia de las Españas / por el doctor__ Médico de cámara con ejercicio del rey Sr. Don Fernando VII. Ex vocal nato de la Real Junta Gubernativa de Medicina, En la Imp. de Sancha, Madrid, 1814. 43 p.; 21 cm. [ADP] 1, 2

1818 NAHARRO, Vicente: Descripción de los juegos de la infancia: los más apropiados a desenvolver sus facultades fisicas y morales, y para servir de abecedario gimnástico / por don__ (con licencia), Imp. que fue de Fuentenebro, Madrid, $1818^{7} .79$ p.: il. con 6 lám.; $18 \mathrm{~cm}$. [AP] 1, 2, 3, 4

1827 [ANÓNIMO $^{8}$ ] La gimnástica del bello sexo...: La gimnástica del bello sexo o ensayo sobre la educación fisica de las jóvenes. Obra escrita originariamente en

\footnotetext{
${ }^{6}$ Traducción de Mariano Iborra.

${ }^{7}$ Clasificado por el Museo Pedagógico Nacional (1915) como un ejemplar (Raro).

${ }^{8}$ Posible autoría del literato romántico José Joaquín de Mora (1783-1864).
} 
Castellano, Lo publica R. Ackermann, Strand, y en su establecimiento en Megico: asimismo en Colombia, Buenos Ayres, Chile, Perú y Guatemala, Londres, $1827^{\circ}$. ( $2^{\mathrm{a}}$ edición) XI-106 p.: il. con 11 lám.; 18 cm. [AP] 1, 2

1840 JULLIEN DE PARÍS, Marco Antonio: Compendio de ensayo general de educación física, moral e intelectual / por con algunas noticias estadísticas sobre el estado actual de la educación primaria en esta provincia, y una nota de libros españoles selectos, para la enseñanza y para uso de la juventud por el C. de R., Socio de número de la Sociedad Económica de Valencia, y premiado con la patente de Socio de Mérito de la misma por la traducción y arreglo de este compendio, Imp. de J. Ferrer de Orga, Valencia, $1840^{10}$. XXX-112 p.; $21 \mathrm{~cm}$. [AP] 1, 2, 3, 5, 6

1842 VILlaLOBOS, Conde de [Francisco de Aguilera Becerril]: Ojeada sobre la jimnasia, utilidades y ventajas que emanan de esta ciencia / escrita por el Excmo. Sr. creador y director del Jimnasio de Madrid, en la Imp. de Yenes, Madrid, $1842^{11} .28$ p.; $\overline{15}$ $\mathrm{cm}$. [ADP] 1, 2, 3

1845 AGUILERA, Fco. Conde de Villalobos: Representación del señor D. Francisco Aguilera, conde de Villalobos, acerca del establecimiento de un Gimnasio Normal en Madrid; dictamen de varios profesores de medicina sobre la utilidad de este establecimiento e informe de la Real Academia de ciencias naturales acerca del mismo asunto, Imp. Colegio de Sordomudos y Ciegos, Madrid, 1845. 46 p.; 16 cm. ${ }^{12}$ [ADP] 1,2, 3

1849 FERNÁNDEZ VILLABRILLE, F.: Instrucción para el pueblo. Cien tratados sobre los conocimientos más útiles e indispensables. Gimnástica / Traducida y adicionada por __ (Entrega 72- Tratado 63), Est. Tip. de Mellado, Madrid, 1849. 16 p.: il. con 35 fig.; pliego doble de impresión en dos columnas, $25 \mathrm{~cm}$. [AGP] 1, 2, 4

1852 APARICI y [BIEDMA], José María: Instrucción para la enseñanza de la gimnástica en los cuerpos de tropas y establecimientos militares. Traducida de la mandada observar en el Ejército francés / por el teniente coronel graduado de Infantería_ director del gimnasio de Guadalajara, Imp. y Estereotipia de $\mathrm{M}$. Rivadeneyra, Madrid, $1852^{13} .222$ p.; 24 cm. [AM] 1, 2, 3, 5

1853 BENZO y SUANES, Antonio: Discurso leído en la Universidad Central / por el Licenciado en Medicina y Cirugía Don__ en el solemne acto de recibir la investidura de doctor en dichas facultades (Necesidad de fomentar la educación física ${ }^{14}$ ), Imp. de José $\mathrm{M}^{\mathrm{a}}$ Ducazcal, Madrid, 1853. 14 p.; 26 cm. [AHM] 1, 2, 5

${ }^{9}$ Palau cita la $1^{\text {a }}$ edición de 1822 (ref. 102384).

${ }^{10}$ Existe una $2^{\mathrm{a}}$ edición Imp. José Mateu Cervera, Valencia, 1845. La obra fue puesta a la venta por pliegos de 32 páginas en $8^{\circ}$ mayor a través de subscripciones.

${ }^{11}$ Esta obra en 1933, aún se exponía a la venta al precio de una peseta, en el "Extracto del Catálogo de obras varias de la Librería Sintes", Ronda Universidad, 4 de Barcelona.

${ }^{12}$ El documento fue publicado en el Boletín Instrucción Pública, núm. 1, 15 de enero de 1845, p. 376-384 y 396-414. También puede localizarse en El Heraldo, 2 de enero de 1845.

${ }^{13}$ Añade un apéndice a la natación, traducción del que publicó en Francia el comandante de Batallón D'Argy: Instruction practique pour l'enseignement élémentaire de la natation dans l'armée (1851), p. 183-206. Contiene un atlas de 27 láminas grandes ilustradas con ejercicios y aparatos gimnásticos.

${ }^{14}$ Citado en la portadilla de la obra. 
1856 RAMÍREZ, Francisco de Borja: Elementos de gimnasia / por__, Imp. de D. F. Ventura y Sabatel, Granada, 1856. 32 p.; 14 cm. [AP] 1, 2

1861 SCHREBER, Daniel Gottlob Moritz: Manual popular de gimnasia de sala médica e higiénica: o Representación y descripción de los movimientos gimnásticos, no exigiendo ningún aparato para su ejecución, pueden practicarse en todas partes y por toda clase de personas de uno y otro sexo. Seguido de sus aplicaciones a diversas enfermedades / por traducción al castellano por D. E. S. O. (Esteban Sánchez de Ocaña) Carlos Bailly - Baillière, Madrid, $1861^{15}$. 130 p.: il.; 16 cm. [AHM y AGP] 1, 2, 3, 4, 5

1863 MORATONES FREIXA, Antonio: Nociones elementales de gimnasia, para jóvenes de ambos secsos / por el profesor de dicho arte e instructor del Ejército__, Imp. de Joaquín Bosch, Barcelona, 1863. 68 p.: 24 lám. con 77 gráficos de ejercicios; $15 \mathrm{~cm}$. [AGP] 1,5

1865 BUSQUÉ y TORRÓ, Sebastián: Gimnástica higiénica, médica y ortopédica o el ejercicio considerado como medio terapéutico / por primer ayudante-médico de Sanidad militar, Imp. Manuel Galiano, Madrid, 1865. XVII-155 p.: 6 lám. de ejercicios; 21 cm. [AHM] 1, 2, 3, 5

RAMIS y TAIX, Joaquín: Una verdad o consideraciones sobre la utilidad de la gimnástica / por__, Imp. Gómez e Inglada, Barcelona, 1865. 47 p.; 15 cm. [ADP] 2, 4

1867 CARLIER, Pedro : Tratado de gimnasia médica y civil / por Caballero de la Real y Militar Orden de San Fernando, director de los gimnasios del Ateneo Mercantil, Industrial y Recreativo y del Colegio Provincial agregado al Instituto de $2^{\mathrm{a}}$ enseñanza de esta capital, Imp. de I. González, Santander, 1867. 129 p.: 2 lám. plegadas de ejercicios y aparatos; $21 \mathrm{~cm}$. [AGP] 1, 2, 5

1868 LLADÓ, Joaquín: Nociones de gimnasia higiénica, aplicables a las escuelas de instrucción primaria de uno y otro sexo como elemento de educación física y de utilidad en todas las edades y para todas las clases de sociedad / por , Lib. de Juan Bastinos e hijo, Editores, Barcelona, 1868. ( $1^{\mathrm{a}}$ edición) ${ }^{16} 143$ p.: 12 lám. al final de texto con 27 figuras; $18 \mathrm{~cm}$. [AP] 1, 2, 3, 4

1873 LÓPEZ GÓMEZ, Salvador: El gimnasio. Tratado teórico-práctico de todos los principios y reglas de aplicación a esta importante parte de la higiene / por_ profesor por oposición en la misma enseñanza, Imp. de R. Baldaraque, Sevilla, $1873^{17}$. 256 p.: 4 lám. con 18 figuras; $21 \mathrm{~cm}$. (contiene un retrato del autor) [AGP] 3, 5

1878 CAMPO, José del: Elementos de educación física: Descripción de los aparatos considerados como más útiles y necesarios para el estudio de la gimnasia higiénica. Relación detallada de los ejercicios que en los mismos se practican y efectos que todos y cada uno de ellos están llamados a producir en el ser humano. Condiciones higiénicas que han de reunir los locales destinados para gimnasio y organización que han de darse a estas clases. Reglas indispensables que deben observar todos los que se dediquen al

${ }^{15}$ Se conocen hasta 1904 un total de 18 ediciones, todas ellas publicadas en la misma casa editorial.

${ }^{16}$ En la $2^{\text {a }}$ edición de 1876, se incorporan "útiles e importantes adiciones" por el Dr. Carlos Ronquillo. Existen además una $3^{\mathrm{a}}$ edición, de 1893, y una $4^{\mathrm{a}}$ edición, de 1912, en Blas Camí, con las citadas adiciones del Dr. Carlos Ronquillo.

${ }^{17}$ Existe una reimpresión del editor Carlos Bailly-Baillière, Madrid, 1873 (238 p.; 3 lám.; $21 \mathrm{~cm}$.). 
estudio de los trabajos gimnásticos y Método para su enseñanza práctica dividido en dos cursos y por lecciones diarias. Escrito expresamente para los establecimientos de instrucción y dedicado al Excmo. Sr. D. Francisco Queipo de Llano, conde de Toreno / por D. _ Imp. de Pedro J. Gelabert, Palma de Mallorca, 1878. 185 p.: il. 9 lám. de ejercicios; $22 \mathrm{~cm}$. [AP] 2,5

1881 LÓPEZ GÓMEZ, Salvador: Breve reseña histórica de la gimnástica en Europa / por D _ Profesor de SS. AA. RR. los Duques de Montpensieur, Director de los Gimnasios provinciales de Sevilla y Málaga, Profesor por oposición, iniciador del proyecto oficial de la Gimnasia en España, colaborador de varios periódicos de Sports nacionales y extranjeros, autor de las obras el Gimnasio, primera y única de su clase publicada en esta ciudad, premiada con medallas en las Exposiciones de París, Sevilla, Cádiz y Pontevedra, Director honorario de los primeros Gimnasios de Madrid, Barcelona, Valencia, Cádiz, Córdoba, Coruña y Bilbao, ex socio honorario del Centro de gimnicología de Barcelonés y corresponsal del Gimnasio Heiser de París, Profesor de los Colegios de primera clase de esta capital: Espíritu Santo, San ramón, San Lorenzo, San Pelagio y San Hilario, Juan Moyano, Sevilla, 1881.39 p.; $21 \mathrm{~cm}$. [ACT] 1, 3, 6

1882 GARCÍA [NAVARRO], Pedro de Alcántara: Teoría y práctica de la educación y la enseñanza. Curso completo y enciclopédico de pedagógica, expuesto conforme a un método rigurosamente didáctico / por $\mathrm{D}$ _ Profesor de Pedagogía en las Escuelas Normales Centrales de Maestros y Maestras -tomo V - (De la educación física), Gras y $\mathrm{Ci}^{\mathrm{a}}$ Editores, Madrid 1882. 608 p.; $20 \mathrm{~cm}$. [AP] 1, 2, 3, 5, 6

1883 SÁNCHEZ GONZÁLEZ DE SOMOANO, José: Tratado de gimnasia pedagógica para uso de las escuelas de primera y segunda enseñanza e institutos / por el profesor en la misma _ de la Asociación de escritores y Artistas, Imp. de Manuel Minuesa de los Ríos, Madrid, 1883. (1ª edición) 279 p.: il. con figuras de ejercicios; 20 cm. [AP] 1,2

1884 PEDREGAL PRIDA, Francisco: Gimnástica civil y militar / por D. Teniente de infantería, con un prólogo de D. José Navarrete, Tip. Manuel Ginés Hernández, Madrid, 1884. ( $1^{\mathrm{a}}$ edición $)^{18}$ XVI-344 p.: il. con 175 figuras; $21 \mathrm{~cm}$. [AGP y AM] 1, 2, 5

1887 ESCUELA CENTRAL DE PROFESORAS Y PROFESORES DE GIMNÁSTICA: Disposición legislativa. Reglamento y Programas Oficiales de la Escuela Central de Profesoras y Profesores de Gimnástica, Tip. de Manuel G. Hernández, Madrid, 1887. XXVI-102 p.; $8^{\circ}$ [AP] 3

MONTANER, Dolores: Gimnasia elemental infantil y escolar / Opúsculo escrito por $\mathrm{D}^{\mathrm{a}}$ _ profesora de $1^{\mathrm{a}}$ enseñanza superior, para uso de las escuelas elementales y de párvulos, Imp. de José Peral, Ocaña, 1887. 44 p.; 19 cm. [AP] 1, 2

SERRATE, Felipe: Tratado Teórico-práctico de los principios y reglas de aplicación de la Gimnástica Médica, Higiénica y Ortopédica y todo cuanto se relaciona con la educación fisica, Est. Tip. Viuda de Delmás, Bilbao, $1887^{19} .192$ p.: il. con 41 láminas y un total de 331 figuras gimnásticas; folio. [AGP] 1,2,3

\footnotetext{
${ }^{18}$ También existe una $2^{\mathrm{a}}$ edición o reimpresión de 1884 .

${ }^{19}$ La contribución de Felipe Serrate a la bibliografía de la educación física fue por partida doble. Por un lado publicó una revista Ilustración Gimnástica (1886-1887) y, al mismo tiempo, y dentro de la misma publicación, introdujo por capítulos, uno de sus más ansiados proyectos, el Tratado Teórico-práctico de los principios y reglas de aplicación de la Gimnástica Médica, Higiénica y Ortopédica y todo cuanto se relaciona con la educación física. Ilustración
} 
1888 BUYLlA y G. ALEGRE, Adolfo A.: Discurso leído en el acto solemne de la apertura de la Academia de Derecho / por_ profesor numerario de Economía, Estadística y Hacienda Pública, Imp. Est. de la "Revista de Asturias", Universidad de Oviedo, Oviedo, $1888^{20} .38$ p.; 25 cm. [AP] 3, 5

DECREF RUIZ, Joaquín: Programa razonado de la asignatura de Educación Física / con arreglo a las explicaciones de Licenciado en Medicina y Cirugía y profesor de dicha asignatura en la Escuela Normal Central de Maestros, Est. Tip. "Sucesores de Rivadeneyra", Madrid, 1888. 16 p.; 18 cm. [AP] 1, 2

1892 PULIDO, Ángel [Pulido Fernández, Ángel]: Educación fisica de la mujer (tesis del Congreso Pedagógico), Imp. de Enrique Teodoro, Madrid, 1892. 28 p.; 19 cm. [AP] 1, 2, 3

1893 FRAGUAS [García Fraguas, José Esteban]: Tratado racional de gimnástica y de los ejercicios y juegos corporales practicables sin aparatos y con ellos en las casas particulares, gimnasios, jardines y en el campo y en las Universidades, Institutos, Escuelas Normales, Y municipales, Academias, Colegios, Hospitales, Sociedades de recreo, etc., etc. / por el Prof.___ Catedrático numerario: Ex Alumno Interno y Jefe Cínico de los Hospitales de Madrid; Socio Honorario de la Sociedad Gimnástica Española; premiado por la Sociedad española de Higiene; Ex Vicepresidente del Ateneo Antropológico de Madrid, etc., etc. Con un prólogo del Excmo. Sr. D. Manuel Becerra, Ex Ministro de Fomento y de Ultramar, iniciador de la educación física oficial, Académico de la de Ciencias Exactas y Naturales, Presidente Honorario de la Sociedad Gimnástica Española, etc., etc. Ilustrada con 800 fotograbados, intercalados en el texto. Tomos I Historia del Ejercicio Corporal y La Mecánica Animal, Est. Tipográfico de Enrique Rubiños, Madrid, 1893. XVI-506 p.: il. con 156 fototipias; $21 \mathrm{~cm}$. [AP] 1, 2, 3, 6

SAN MARTÍN SATRÚSTEGUI, Alejandro: Discurso leido en la Universidad Central en la solemne inauguración del curso académico de 1893 a 1894 / por el__ catedrático de Medicina. Notas sobre la educación física, Imp. Colonial a cargo de G. Giménez, Madrid, 1893.96 p.; $27 \mathrm{~cm}$. [AP] 1, 2, 3, 5, 6

1894 LÓPEZ GÓMEZ, E. Salvador: Manual de ejercicios gimnásticos: para uso de los Institutos y Escuelas Normales / por__ Catedrático numerario de esta asignatura en el Instituto Provincial, Profesor de la misma enseñanza en la Escuela Normal profesional de Maestros de Sevilla y Exvocal del Tribunal de exámenes en la Escuela Central de Gimnástica, etc., etc., Imp. Gironés y Orduña, Sevilla, 1894. 195 p.: il. con 44 figuras; 18 cm. [AP] 2

1895 PEDREGAL PRIDA, Francisco: La educación gimnástica / por__ Capitán del Ejército, ex profesor numerario de la Escuela Central de Gimnástica, Imp. de los Hijos de M. G. Hernández, Madrid, 1895. (1 ${ }^{\mathrm{a}}$ edición) ${ }^{21} 379$ p.: il.; $23 \mathrm{~cm}$. [AP] 2

SANZ ROMO, Marcelo: (Sport de la infancia y de la juventud) Manual de gimnástica higiénica y juegos escolares / por el profesor__ Ex Catedrático del Instituto de Logroño, Imp. de los Sucesores de Cuesta, Madrid, 1895. (1 ${ }^{\text {a }}$ edición) ${ }^{22} 319$ p.: il.; 18 cm. [AP] 2

Gimnástica, subtitulada como Tratado Teórico-práctico de los principios y reglas de aplicación de la Gimnástica Médica, Higiénica y Ortopédica y todo cuanto se relaciona con la educación física (quincenal, en folio mayor de 8 páginas cada núm. Est. Tipo-litográfico de Viuda de Delmas, Bilbao (1886-87). El primer número de la revista apareció el 1 de marzo de 1886 y el último, núm. 24, el 15 de agosto de 1887.

${ }^{20}$ El discurso trata críticamente sobre "la educación física y moral de las Universidades".

${ }^{21}$ Existen dos ediciones más: la 2a , de 1897 , y la $3^{\mathrm{a}}$, de 1901. 
1896 CALATRAVEÑO, Dr. [Calatraveño Valladares, Fernando]: Necesidad e importancia de la educación fisica: Trabajo leído en la Asociación Nacional de Gimnástica en el Festival celebrado por la misma el 25 de abril de 1896, Imp. de los Sucesores de E. Cuesta, Madrid, $1896^{23} .23$ p.; $18 \mathrm{~cm}$. [AHM] 2

1899 TISSIÉ, Ph. [Dr.]: La fatiga y el adiestramiento fisico. Traducción española de Ricardo Rubio, Librería de Fernando Fé / Librería de Victoriano Suárez; Imp. y Fotograbado de Enrique Rojas, Madrid, $1899^{24}$. XIX-451 p.: il.; 19 cm. [ACT] 2, 3, 5, 6

1900 BARRILERO FOSSAS, Peter ${ }^{25}$ : (Biblioteca de la Educación Física Nacional) Juegos gimnásticos. Cuaderno núm. 1. El Cricket, Imp. de los hijos de M. G. Hernández, Madrid, s.a., (1900) ${ }^{26} 14$ p.; $16 \mathrm{~cm}$. [AD] 1, 2

CLERIOT, E. Dr.: Manual de gimnástica higiénico-educativa: para usar con acierto la Polea Universal / por el Dr._ _ Imp. de los hijos de M. G. Hernández, Madrid, 1900. 36 p.: il. 19 figuras; $15 \mathrm{~cm}$. [AGP] $1,2,5$

1901 UTOR SOTOMAYOR, Eduardo: (Sobre la gimnasia escolar elemental e higiénica) Memoria leída y aprobada en la Universidad Central para optar al grado de doctor de Medicina y Cirugía / por Don__, Est. Tip. "El porvenir", Algeciras, 1901²7. 41 p.; $25 \mathrm{~cm}$. [AP y AHM] 1, 2

1902 FEDERACIÓN GIMNÁSTICA ESPAÑOLA: (Federación Gimnástica Española) Asamblea de Zaragoza, Imp. J. Cunill, Barcelona, $1902^{28}$. 166 p.; 18 cm. [ACT] 2, 3, 4

FEDERACIÓN GIMNÁSTICA ESPAÑOLA: Ferias y Fiestas populares de Ntra. Sra. de las Mercedes. Programa y Reglamentos de los concursos que la Federación Gimnástica Española ha de realizar en el Campo de Juego del Parque, Imp. José Cunill, Barcelona, 1902. 15 p.; $20 \mathrm{~cm}$. (folleto) [AD] 1,2

1903 BARRERAS, Julián de las: Los ejercicios gimnásticos en el bello sexo / Memoria de__ premiada en público concurso ${ }^{29}$, Los Deportes, Barcelona, $1903^{30} .39$ p.: Contiene un retrato del autor; $20 \mathrm{~cm}$. [AGP] 1,2

VIADA, Antonio: (Manuales Romo y Füssel) Manual de sport / por_ con un prólogo de Alejandro Saint-Aubin. Historia.- Generalidades.- Hípica.- Ciclismo.- Automóvil.Caza.- Pesca.- Esgrima.- Tiro.- Regatas.- Foot-ball.- Pelota vasca.- Tennis.- Cricket.Base-ball.- Basket-ball.- Push-ball.- Golfo.- Hockey.- Crosse.- Croquet.- Bochas.- Billar.Gimnasia.- Boxeo.- Lucha.- Skating.- Natación.- Pedestrismo, Ed. Adrian Romo, Madrid, 1903. XI-772 p.: il. ; 17 cm. [AD] 1, 2, 3, 5, 6

${ }^{22}$ Existe una $2^{\mathrm{a}}$ edición ampliada en la Est. Tip. de Juan Pérez Torres, Madrid, 1915.

23 Vid. Calatraveño, F. Dr.: "Necesidad e importancia de la educación física", La Regeneración Física, 1 de junio de 1896, núm. 17, p. 2. (Continua en los números 14, 15, 16, $17,18$ y 21$)$

${ }^{24}$ Existe otra edición en la Biblioteca Científico Filosófica de Daniel Jorro Editor.

${ }^{25}$ Nombre con el que se firma al final de la obra.

${ }^{26}$ El prólogo está fechado en 1900.

${ }^{27}$ En la Bibliografia y material de enseñanza, publicada en 1915 por el Museo Pedagógico Nacional, se cataloga la obra como un ejemplar "raro".

${ }^{28}$ No conocemos la portada de la obra.

${ }^{29}$ La obra fue premiada en concurso público de la Federación Gimnástica Española.

${ }^{30}$ En la tapa o cubierta indica 1904. La obra está firmada al final del texto, en agosto de 1902. 
1904 SAMPÉREZ ARROYO, Luciano: Manual de Gimnasia Nacional higiénico cívico - militar / por D. _ Profesor numerario de Gimnástica del Instituto general técnico de Badajoz; de las Escuelas Municipales y del Hospicio; Comandante de Zapadores Bomberos; Ex profesor de Gimnasia militar del Batallón de Cazadores de Tarifa y de los Regimientos de Castilla y Gravelinas, y en la actualidad con igual categoría, para las tropas que guarnecen Badajoz, por R. O. de 28 de junio de 1897. Premiado, entre otras distinciones profesionales, con la Medalla de Oro, primer premio, como Director del Concurso Internacional de Gimnasia, promovido por el Excmo. Ayuntamiento de Badajoz en Agosto de 1892: Medalla de Plata del Gimnasio "Lauret" de Porto (Portugal); Diploma de honor como Maestro del "Club Gimnástico Portugués" de Lisboa, en el concurso promovido por el "Real Gimnasio Club" de dicha población, en Mayo de 1885. $1^{a}$ parte, Tip y Enc. La Minerva Extremeña, Badajoz, 1904. 64 p.: il. con figuras de ejercicios gimnásticos y un retrato del autor; $15 \mathrm{~cm}$. [AP] 1,2

1905 ROMERO, Vicente: Cartilla-compendio de gimnasia racional a pie firme $y$ manos libres / por D__ (Biblioteca de Educación Física Nacional), Imp. de los Hijos de M. G. Hernández, Madrid, 1905. 65 p.: il. ; $16 \mathrm{~cm}$. [AGP] 1, 2

1907 KUMLIEN, L. G.: La gimnasia para todos: "Para llegar a viejo y con buena salud, haced todos los días algunos minutos de ejercicios sin aparatos según el método sueco", Librería Gutemberg de José Ruiz, Madrid, s.a., (1907) ${ }^{31} 118$ p.: il., 3 h. de lám. pleg.; $18 \mathrm{~cm}$. [AGP] 3, 4, 5

1908 ARNULPHY, Víctor, Dr.: La salud por la respiración: Curso Completo de Gimnasia respiratoria. Seguido de un manual de terapéutica respiratoria y un importante capitulo sobre la respiración sportiva y atlética. Traducido de la segunda edición francesa por José Roda Rodríguez, Imp. de Juan Fernández Murcia, Almería, $1908^{32} .77$ p.; 21 cm. [AHM y AGP] $1,2,3,4,5$

SARDÁ SALVANY, Félix: L'sport católich: Conferencia en el Ateneu de Sant Lluis Gonçaga, de la barriada de Sant Andréu de Palomar (Barcelona), ab ocasió de les Bodes d'or de dita fervosa Associació, celebrades lo día 28 de juny del present any, llegida / per lo R. D. _ Pvre., Director de la "Revista Popular". Ab llicencia esclesiàstica, Lib. Tip. Católica, Barcelona, 1908. 19 p.; $15 \mathrm{~cm}$. [ADP] 1,2

1910 ESTADELLA ARNÓ José: Educación Física en las escuelas de primera enseñanza / por_ Médico-Cirujano, titular por oposición, profesor de Gimnástica, profesor libre de Fisiología e Higiene, Imp. "Juventut", Lérida, $1910^{33} .58$ p.; $21 \mathrm{~cm}$. [AP] 1, 2

LANGLOIS DU FEU, V.: La educación física como base y norma de toda pedagogía racional y biológica (tema presentado en el Congreso de Primera Enseñanza celebrado en Barcelona en el año 1909-10), Imp. Tasis, Barcelona, 1910. 14 p.; 24 cm. [AP] 2

31 Probablemente, la $1^{\text {a }}$ edición corresponda hacia 1901. Asimismo, se han localizado ediciones de 1905, 1913 y 1919, además de numerosas reimpresiones, algunas sin año.

${ }^{32}$ Se conocen varias ediciones. La $5^{\text {a }}$ en la Imp. y Papelería Sampere, Almería, 1921 contiene un apéndice de José Roda Rodríguez que habla de la "Utilidad general de la gimnasia respiratoria" y de la "Higiene cotidiana", p. 107-137.

${ }^{33}$ Puede localizarse la totalidad de la obra, en capítulos o partes, en el Boletín del Colegio de Médicos de Lérida, números de los años 1910 a 1911. 
1911 BARBA, Alejandro: (Manuales Soler.- XCVI) Foot Ball, Basse Ball y Lawn Tennis / por_ Dibujos de José Cuchy, Ed. Sucesores de M. Soler, Barcelona / Buenos Aires, s.a., (1911) 151 p.: il. con 39 grabados; $16 \mathrm{~cm}$. [AD] 1, 4

MINISTERIO DE LA GUERRA: Reglamento provisional de gimnasia para infantería, Talleres del Depósito de la Guerra, Madrid, 191134. 207 p.: il. con 119 ejercicios gimnásticos fuera de texto y 5 lám. de construcción de aparatos; $19 \mathrm{~cm}$. [AM] 1, 2, 3, 5

1912 EXPLORADORES DE ESPAÑA, Los (Boy Scouts Españoles): Estatutos y reglamento interior, provisionales, Talleres Depósito de la Guerra, Madrid, 1912. 46 p.; 21 cm. [AP y AM] 1, 2, 4, 5

REVUELTA FERNÁNDEZ, Adolfo: Necesidad e importancia de la educación fisica. Memoria premiada por la Facultad de Medicina de Santiago en el Certamen Literario de 1912 / por_ Profesor del Instituto y de la Escuela Normal Superior de Maestros, Tipografía Galaica, Santiago, 1912. 36 p.; $20 \mathrm{~cm}$. [ADP] 2

SAIMBRAUM, Dr.: Salud, fuerza y belleza por medio de la Gimnasia Sueca,

Sociedad General de Publicaciones, Barcelona, 1912. ( $1^{\text {a }}$ edición $)^{35} 145$ p.: il. con 30 ejercicios fotografiados; $19 \mathrm{~cm}$. [AGP] 4

1913 SANZ ROMO, Marcelo: Ensayo de una higiene deportiva o de los deportes ante la higiene, Imp. "La Correspondencia Militar", Madrid, $1913^{36} .154$ p.; 17 cm. [ACT] 1, 2, 6

F. ZABALA, José (Fernández Zabala, José): (Club Alpino Español) Deportes de nieve / por__ Prólogo y colaboración de Manuel Amezua. Ilustraciones de Antonio Prast, Imp. de José F. Zabala Madrid, 1913. 103 p.: il. con dibujos y fotografía; $18 \mathrm{~cm}$. [AD] 1

1914 BELLÍ CASTIELL, Epifanio: Modificaciones que imprime en la anatomía del cuerpo humano, el ejercicio físico y acción del mismo sobre algunos fenómenos de la vida fisiológica: Memoria que para obtener el grado de doctor / presenta el doctorando Artes Gráficas Sol y Benet, Lérida, s.a., (1914). 63 p.; 21 cm. [AHM] 6

DECREF y RUIZ, Joaquín: Kinesiterapia: Manual de técnica de amasamiento y gimnasia médica y sus aplicaciones a las enfermedades del aparato locomotor / por el Doctor D. Profesor encargado de Kinesioterapia y Electroterapia en el Hospital Clínico de la Facultad de Medicina de la Universidad Central. Especialista en las enfermedades del aparato locomotor. Director del Instituto de Ortopedia, Fisioterapia y Radiografía. A. C. de las Reales academias de Medicina de Madrid, Sevilla y Cádiz, etc., etc., etc., Adrian Romo Editor, Madrid, 1914. 255 p.: il.; 17 cm. [AHM] 1, 2, 3, 5, 6

ELÍAS JUNCOSA, José: (Los sports) Football asociación / por_ (corredisses) con un prólogo de Hans Gamper ${ }^{37}$, R. Tobeña impresor, Barcelona, 1914 ${ }^{\overline{38}}$. (1 $1^{\text {a }}$ edición) 94 p.: il.; $17 \mathrm{~cm}$. [AD] 1, 2, 4, 5

${ }^{34}$ Existen otras ediciones de 1916, 1918 y, probablemente, otra de 1924. En ocasiones se presenta en dos volúmenes por separado: tomo I de texto y tomo II de láminas.

${ }^{35}$ Hemos localizados al menos dieciséis ediciones entre 1912 a 1939. Asimismo, existe una decimoséptima de 1944. Conocemos también, que las ediciones de 1932 (decimotercera) y 1934 (decimocuarta), tuvieron ambas una tirada de 10.000 ejemplares, y que la de 1937 (decimoquinta) de 5.000. Algunas ediciones pueden encontrase publicadas por la Sociedad General de Publicaciones, S.A. y, a partir de la decimotercera edición, en HYMSA.

${ }^{36}$ A este primer tomo continuaba otro, editado en 1916, de 152 páginas, en $8^{\circ}$.

${ }^{37}$ El prólogo es fechado en Barcelona, 15-VII-1913. 
SANZ ROMO, Marcelo y ESCRIBANO, Roberto: Curso teórico y práctico de educación fisica / por D. _ Ex profesor del Instituto de Logroño, Profesor de Educación Física de la Escuela Normal de Maestros y del Centro del Ejército y de la Armada y _ Maestro de Primera enseñanza, Alumno de la facultad de Medicina y Redactor de "La Enseñanza", Comprende: Educación Física del niño.- Gimnasia educativa, sistema Ling.- Juegos escolares.Deportes, Imp. de la Enseñanza, Madrid, $1914^{39} .184$ p.: il.; $19 \mathrm{~cm}$. [AP] 1, 2

1915 MUSEO PEDAGÓGICO NACIONAL: Bibliografía y material de enseñanza. Educación fisica. Higiene escolar, R. Rojas, Madrid, 1915. 358 p.; 23 cm. [ABD] 1, 2, 3, 6

OSES LARUMBE, José: Juegos de patio para niños... Los grandes y pequeños deportes al aire libre, Lib. de Perelló i Vergés, Barcelona, 1915. 183 p.: il.; 17 cm. [AP] 1, 2, 5

1916 NAVARRO, Emilio: Álbum histórico de las sociedades deportivas de Barcelona / por__ Prólogo de D. Narciso Masferrer, Imp. José Ortega, Barcelona, s.a., (1916) 251 p.: il. con fotografías; $22 \mathrm{~cm}$. [ACT y AD] 1, 5,

1917 SPITZY, Hans Dr.: La educación fisica del niño. Traducción directa del alemán por el Dr. D. Manuel M. Bastos Ansart, Profesor auxiliar de Clínica Quirúrgica de la Facultad de Medicina de Madrid, Casa Ed. Calleja, Madrid, 1917 $7^{41} 604$ p.: il. con numerosas fotografías; $17 \mathrm{~cm}$. [AP] 1, 2, 3, 5, 6

1919 DECREF [RUIZ], Joaquín: (Biblioteca vida y ciencia) Necesidad de organizar e implantar en España los laboratorios de deportes: Conferencia dada en la Sociedad Española de Gimnástica / por el Dr._ de la Real Academia Nacional de Medicina, Tipografía "La Exposición", Sevilla, 1919. 18 p.; 24 cm. [AHM] 1, 2, 3, 6

MULLER, J. P.: Mi sistema. Quince minutos de trabajo diario para la salud / por__ ex teniente de ingenieros de Ejército Danés, autor de "El libro al aire libre", "Mi sistema para señoras", etc. Con ilustraciones cinematográficas y un cuadro de empleo del tiempo. Versión Castellana de Alberto Conradi, Médico $1^{\circ}$ del Cuerpo de Sanidad Militar, Adrian Romo, Editor, Madrid, $1919^{42} .111$ p.: il. contiene un retrato del autor; $22 \mathrm{~cm}$. [AGP] 1, 2, 4, 5

1924 ALCÁNTARA, Paulino: Mis memorias y consejos prácticos para el entrenamiento, Imp. Garrofé, Barcelona, $1924^{43} .109$ p.: il. con fotografías; $19 \mathrm{~cm}$. [AD] 4

${ }^{38}$ Esta obra dispone de otras ediciones y/o reimpresiones que pueden encontrarse en la Colección de "Los Sports", núm. 1 de Lib. Sintes, Barcelona, s.a. (112 p.: il.; 17 cm.)

${ }^{39}$ Existe una $2^{\mathrm{a}}$ edición de 1915 y, una $3^{\mathrm{a}}$, de 1916.

${ }^{40}$ En la tapa figura Álbum Histórico de las Sociedades deportivas de Barcelona, 1916. En las indicaciones iníciales el autor fecha la obra en noviembre de 1916. Al final del libro una nota del autor indica modificaciones hasta la fecha de impresión en febrero de 1917.

41 Existe una segunda edición de la misma editorial sin fecha de impresión, que probablemente pudiera ser de 1920 (417 p.: il.; 20 x $16 \mathrm{~cm}$.)

${ }^{42}$ Existen varias ediciones o reimpresiones sin fecha, además, de una edición de 1936: "Nueva edición corregida y aumentada con 120 ilustraciones". La primera edición danesa de $\mathrm{Mi}$ sistema fue impresa en 1904. En España, posteriormente a 1919 siguieron numerosas reimpresiones y nuevas ediciones, al menos se conocen una fechada en $1936 \mathrm{y}$, otras dos diferentes, sin año. La última edición conocida fue impresa en por la Librería Internacional de Romo, Madrid, 1961. El prólogo está fechado en 1917.

${ }^{43}$ En la última página se indica: "La censura militar revisó este libro". 
CARBÓ i SANTAEUlARIA, Daniel: Historial del F. C. Barcelona, 1899-1924 / per___ (correcuita), Imp. Costa, Barcelona, 1924. 2 v. de 464 p. y 494 p.: il. con fotografías; $19 \mathrm{~cm}$. [AD] 1, 2, 3, 6

ELEIZEGUI, Dr. José de: Los juegos en la infancia: Guía médico-pedagógica para padres y maestros, Sociedad General de Publicaciones, Barcelona s.a., (1924) 151 p.; 20 cm. [AP] 2, 3, 5

ESCUELA CENTRAL DE GIMNASIA: Memoria de los cursos 1920, 1921, 1923, Imp. del Colegio de María Cristina, Toledo, s.a., (1924) 159 p.: il. con numerosas fotografías; $27 \mathrm{~cm}$. [AM] 2, 5

MINISTERIO DE LA GUERRA. ESCUELA CENTRAL DE GIMNASIA ${ }^{44}$ : (Publicaciones del Directorio Militar. Ministerio de la Guerra. Escuela Central de Gimnasia.) Cartilla Gimnástica Infantil, Sucesores de Rivadeneyra, Madrid, 1924. 63 p.: il. con 13 lám. pleg. de ejercicios; $19 \mathrm{~cm}$. [AP] 1, 2, 4

1925 COMITÉ OLÍMPICO ESPAÑOL: Memoria liquidación y balance de la participación de España en los Juegos de la VIII ${ }^{a}$ Olimpíada. Cuadro general de clasificación de resultados (Aprobado por el Comité Olímpico Español en sesiones celebradas los días 13 de agosto y 2, 5, 6 de octubre de 1925), Imp. F. Giró, Barcelona, 1925. 45 p.: 1 lám. desplegable; $24 \mathrm{~cm}$. [AD] 2, 5

HEBERT, Georges: El sport contra la educación física / por__ Ex teniente de Navío francés, antiguo director del Colegio de Atletas de Reims. Traducido por G. Pérez Acosta, Coronel de Artillería, Imp. Mercantil, Barcelona, 1925. 133 p.; 17 cm. [ACT] 1, 2, 3, 5, 6

SUÁREZ ÁlVAREZ, Rodrigo: Gimnasia educativa sueca / por_Capitán de infantería, Profesor de gimnasia, Imp. Colegio de María Cristiana, Toledo, 1925. Dos tomos: I. 315 p.; 23 cm. / II. de ilustraciones; 248 figuras. [AP] 2, 3

1926 LLORCA RADAL, Jesús: (Junta para la Ampliación de Estudios e Investigaciones Científicas) Juegos rítmicos en la escuela / por__, Junta para la Ampliación de Estudios e Investigaciones Científicas, Madrid, 1926. Anales XVIII de la Junta para la Ampliación de Estudios e Investigaciones Científicas, Madrid, 1926; (Tomo II, memoria 18, p. 320 a 335); $23 \mathrm{~cm}$. [AP] 1, 2, 3

1927 BATISTA i ROCA, Josep $\mathrm{M}^{\mathrm{a}}$ : (Col·lecció Popular Barcino.- XIV) Manual d'excursionisme / per__ _, Ed. Barcino, Barcelona, 1927. (2a edición) 156 p.: il.; 16 cm. [AD] 5, 6

BLANCO SÁNCHEZ, Rufino: Bibliografía general de la educación fisica: con datos copiosos referentes a la biología, antropología, anatomía, fisiología, higiene, eugénica, puericultura, paidología, pedagogía y otras ciencias fundamentales del ejercicio corporal educativo / por el Doctor D._ Profesor de Pedagogía en la Escuela de Estudios Superiores del Magisterio de Madrid, Hernando, Madrid, 1927. Tomo I. LXI-1007 p. (Suplemento, p. 517 a 917 / Apéndice de últimas adiciones, p. 920 a 1007), tomo II 453 p.; $26 \mathrm{~cm}$. (Índices) [ABD] 1, 2, 3, 6

CONFEDERACIÓN DEPORTIVA DE CATALUÑA: Estatutos de la Confederación Deportiva de Cataluña: Reglamentos de premios y composición de la entidad (ejercicio 1926-1927), Confederación Deportiva de Cataluña, Barcelona, 1927. 44 p.; 15 cm. [AD] 5

CONDO GONZÁLEZ, Augusto: Gimnasia e hidroterapia en el desarrollo infantil. Medios fáciles de aplicación en las clases proletariadas / por_ Comandante de Infantería, fundador de la Revista pedagógica "La Educación Física", ex profesor de

\footnotetext{
${ }^{44}$ Los autores de la Cartilla fueron José Canillas Hernández-Lena y Rodrigo Suárez Álvarez.
} 
Gimnasia de varios Centros oficiales y particulares, Suc. Rivadeneyra, Madrid, 1927. (1 ${ }^{\mathrm{a}}$ edición $)^{45} 94$ p.: il. ; $21 \mathrm{~cm}$. [AP] 1, 2

DIRECCIÓN GENERAL DE PREPARACIÓN EN CAMPAÑA: Reglamento de instrucción física para el ejército, Talleres del Depósito de la Guerra, Madrid, $1927^{46} .3$ Tomos: I. 238 p., II. 103 p., III. 139 p.; il. con lám. al final de texto; 18 cm. [AM] 5, 6

ESCUELA CENTRAL DE GIMNASIA: (Escuela Central de Gimnasia) Foot-ball Rugby: Reglamento, Imp. Colegio María Cristina, Toledo, 1927. 74 p.: il.; 16 cm. [AM y AD] 2, 5

1928 CADENAS CAMPO, Cándida: Conferencia dada por la inspectora de $1^{\mathrm{a}}$ enseñanza_Condecorada con la Encomienda de Alfonso XII por R. O de 4 de marzo de 1927, en el Cursillo de Información sobre Educación Física Femenina que para maestras Nacionales de $1^{a}$ enseñanza organizó del 23 al 28 de Marzo de 1927 en Zamora, Imp. de Manuel Espias ("El Arte"), Zamora, 1928. 47 p.: il. con tres fotografías pegadas; $20 \mathrm{~cm}$. [AP] $1,2,3,5$

VV. AA.: (Catalunya i Balears) Llibre d'or del futbol català: amb unes interessants notes gràfiques $i$ informatives a honor del Futbol Nacional i Internacional; edició recomanada i patrocinada per la Federació Catalana de Futbol Associació, B. Ribes Bancells: Edicions "Monjoia", Barcelona, 1928. 679 p.: il. con fotografías; $30 \mathrm{~cm}$. [AD] 1, 2, 3

1929 COMITÉ NACIONAL DE CULTURA FÍSICA: (Comité Nacional de Cultura Física. Escuela Central de Gimnasia) Curso de información para comandantes del ejército sobre educación física, ciudadanía y premilitar, Imp. del Colegio de María Cristina, Toledo, 1929. 145 p.; $19 \mathrm{~cm}$. [AM] 1, 2, 5

SOTO BARRERA, Joaquín: (Núm. 10 El libro del pueblo, Serie VII-9) Historia del fútbol en España / por__ Compañía Ibero-Americana de Publicaciones, S. A. Madrid, 1930. 54 p.: il. con fotografías; $18 \mathrm{~cm}$. [ACT y AD] 1, 2, 4, 6

1930 CASALS SOLER, M.: Gimnasia, juegos y deporte: Manual de educación fisica recreativa, Lib. e Imprenta Casals, Barcelona, $1930^{47} .184$ p.: il. con 93 figuras; $21 \mathrm{~cm}$. [AP] 1, 2, 4

OLAVARRIETA, J. B.: (Pequeña Enciclopedia Práctica, núm. 4) La salud por el ejercicio, Lib. Bergua, Madrid (Tip. y Enc. de Senén Martín Díaz, Ávila), s.a., (1930- $4^{\mathrm{a}}$ edición $)^{48} 63$ p.: 1lám. final plegable al final de texto con 34 ejercicios; $18 \mathrm{~cm}$. [AGP], 1, 2, 4

RICO, Pedro: El "sport" en España, amateurs y profesionales: Educación, distracción, espectáculo. Prólogo del Dr. Bartrina. Ilustraciones de Ríu, Ed. Javier Morata, Madrid, 1930. ( $1^{\mathrm{a}}$ edición) 201 p.: il.; $19 \mathrm{~cm}$. [ACT] 2, 3, 5, 6

1931 MOLLÁ, Doctor: La mujer y el deporte / por el Doctor , Lib. Médica de R. Chema y Compa, Madrid, 1931. 149 p.; 16 cm. [ACT] 1, 2, 5, 6

${ }^{45}$ Existen dos ediciones: la $2^{\mathrm{a}}$ impresa en la Imp. Cleto Vallinas, Madrid, 1928 y, la $3^{\mathrm{a}}$, en 1931. En 1

a portada de la $2^{\mathrm{a}}$ edición se cita: "Memoria premiada con el Premio de Honor, concedido por S. M. El Rey (q. D. g.) en el XIV Concurso de Higiene Popular y Cultura Física, celebrado por la Unión Médica Gaditana".

${ }^{46}$ Debido a que el Reglamento era muy voluminoso se publicó una edición reducida con el nombre de Compendio del Reglamento de instrucción física para el ejercito, Talleres del Depósito de la Guerra, Madrid, 1928 (173 p.). Del Reglamento se editaron 12.000 ejemplares.

${ }^{47}$ Existen algunas ediciones que no disponen de fecha de impresión.

${ }^{48}$ Se han localizado ejemplares que citan Bergua, Juan B.: La Salud por el ejercicio, Sáez Hermanos, Madrid, s.a. ( $3^{\mathrm{a}}$ tirada) 
1932 AJUNTAMENT DE BARCELONA: (Comissió de Cultura) L'obra de les colònies escolars, banys de mar $i$ semicolònies per als alumnes de les escoles de Barcelona, 1906-1931, maig de MCMXXXII, Ajuntament de Barcelona, Barcelona, 1932. 222 p.: il. con fotografías; $23 \mathrm{~cm}$. [AHM] 2, 3, 5

1933 F. TRAPIELLA [Francisco Javier Fernández Trapiella]: (Colección Bibliografía Militar, tomo LVI) Ciencia y arte de la educación física, Imp. de Rodríguez y Compa Toledo, 1933. (1 ${ }^{\text {a }}$ edición) ${ }^{49} 193$ p.: il. con numerosas fotografías; $19 \mathrm{~cm}$. [AGP] 3, 4

1934 LLOBERA, Pedro: El espíritu deportivo de las Escuelas Nuevas / por profesor de Escuelas Nuevas en el extranjero, Imp. Antonio Porta, Barcelona, 1934. 20 p.; $20 \mathrm{~cm}$. [AP] 5

1935 LLAVERÍAS ROVIROSA, Amadeo: Catálogo de la Biblioteca del Gimnasio de Colón / formado por_, Lib. Anticuaría de Antonio Palau y Dulcet, Barcelona, $1935^{50}$. 264 p.: il.; $21 \mathrm{~cm}$. [ABD] 1, 2

1936 MORAGAS RAMÍREZ, Emili y SURIOL TORRA, Josep: Tres mil quinientos casos de traumatismo de fútbol: Registro estadístico de los mismos con clasificación de lesiones y su distribución anatómica-topográfica y deportiva / por los doctores

Director Clínico de la Mutualidad Esportiva de Catalunya, Profesor Libre de Traumatología deportiva, Cirujano Jefe del Hospital de Sabadell; y__ Jefe del servicio médico antropométrico de la Mutual Esportiva de Catalunya, Profesor oficial de Educación Física, Académico correspondiente de la Academia de Medicina de Barcelona, s. e., Barcelona, 1936. 48 p.: 24 cm. [AHM] 1, 2, 4, 6

SOLER DAMIANS, J.: (Biblioteca Sociológica Contemporánea) Assaig d'un pla general d'educació física. Pròleg de F. Pujol i Algeró, Ed. Norma, Barcelona, 1936. 82 p.; $22 \mathrm{~cm}$. [ACT] 1, 2, 3, 6

1937 [CRESPÍ CÁNAVES, Pedro y QUÍLEZ, Leopoldo] ${ }^{51}$ : (Publicaciones del Colegio Oficial del Magisterio Primario de Baleares) Normas de educación física infantil, Tip. Católica Vda. de S. Pizá, s.1., 1937 52 p.: 11 lám. de ejercicios al final de texto; $22 \mathrm{~cm}$. [AP] 2,5

1938 BUCHELI, Joan: (Esports) Basquetbol / per_ President de la Federació Catalana de Basquetbol, Edicions del Departament de Cultura del Comissariat d'Educació Física i Esports de la Generalitat de Catalunya, Barcelona, 1938. 63 p.: il.; 17 cm. [AD] 1, 2

PASO ANDRÉS, Antonio: Cartilla de Educación Física, Imp. Lenin, Madrid, 1938. 83 p.: il.; $16 \mathrm{~cm}$. [AM] 1, 2

${ }^{49}$ De esta obra se constatan varias ediciones impresas en el período franquista: 1942, 1944, 1952 y una $4^{\mathrm{a}}$ de 1954 . Estas ediciones fueron reeditadas y ampliadas como respuesta a múltiples solicitudes.

${ }^{50}$ Vid. $1^{\text {a }}$ edición de este Catálogo con la bibliografía registrada hasta 1910, en Llaverías Rovirosa, Amadeo: Catálogo de la Biblioteca del Gimnasio de Colón, Imp. Fiol, Barcelona, 1910.

${ }^{51}$ Autores citados en el interior de la obra.

${ }^{52}$ En el interior se cita: "Estas Normas de Educación Física Infantil se dan a la luz, por acuerdo de la Junta de Gobierno del Colegio Oficial del Magisterio primario de Baleares, para guía y orientación de los maestros nacionales en la patriótica obra de formación física de los niños españoles, en quienes España grande, que amanece bajo el caudillaje invicto del Generalísimo Franco, pone las esperanzas más ciertas de su gloria inmortal". 
VILLALBA RUBIO, Ricardo: (Publicaciones del Ministerio de Educación Nacional) Nociones teóricas para la Educación Física / por D_ Teniente coronel de Infantería, Imp. Hijos de Santiago Rodríguez, Burgos, $1938^{53} .152 \overline{\mathrm{p}}$; $21 \mathrm{~cm}$. [AP] 1, 2, 3

\section{DISCUSIÓN EN TORNO A LA BIBLIOGRAFÍA PRESENTADA}

Para valorar el alcance y la contribución de la bibliografía en el proceso de institucionalización de la educación física y el deporte en España, presentamos una discusión en torno a las cien obras que hemos considerado más relevantes entre el período de 1800 a 1939 . Creemos que ello ha de permitir una mejor interpretación en cuanto a la difusión e impacto social y académico que protagonizo la bibliografía objeto de estudio. Por tanto defendemos que las cien obras de referencia aquí presentadas fueron las que más impacto intelectual y popular tuvieron en su ámbito específico y las que más influyeron en el entorno sociocultural de su época. Para la valoración de este repertorio bibliográfico nos hemos regido por los criterios de la originalidad de contenidos y métodos, por la orientación de las obras y el valor del objeto perseguido, por la trascendencia intelectual y profesional, por el impacto intelectual y el alcance social, por el carácter ideológico dominante y por el rigor técnico y científico.

La producción de la bibliografía propia de la educación física se vio incrementada en la década de 1880 a 1889. Sin embargo, los tratados gimnásticos de este período son de poca importancia técnica, ya que mantenían sus vínculos con el método de Francisco Amorós (1770-1848) y no representaban ninguna evolución destacable (Climent, 2001; Hernández, 1988). El cambio substancial en la producción bibliográfica se concentró en la década de final del siglo XIX, gracias a un empuje regeneracionista que fue auspiciado desde sectores higiénicos, pedagógicos, militares, políticos e intelectuales (Torrebadella, 2000a). Este momento coyuntural fue aprovechado por el propio ámbito profesional de la educación física que veía como sus aportaciones literarias y técnicas eran bien acogidas y como sus derechos profesionales en el ámbito educativo eran fortalecidos por otros sectores relevantes (Torrebadella, 2011c).

Coincidimos con Piernavieja (1962) que "la bibliografia gimnástica decimonónica no es muy rica ni, sobre todo, valiosa" (p. 143). Ello también podría sentenciarse en cuanto a la bibliografía entre 1900 y 1939. En general, la literatura científica, pedagógica y popular gimnástico-deportiva se vio afectada por la carencia de no poseer un sistema propio de educación física. Aunque la coyuntura regeneracionista facilitase un ambiente propicio para producir y difundir la literatura propia de la educación física de carácter científico, técnico y doctrinal,

${ }^{53}$ Esta publicación también puede encontrarse en Ministerio de Educación Nacional: Curso de orientaciones nacionales de la primera enseñanza, celebrado en Pamplona, del 1 al 30 de junio, segundo año triunfal, Hijos de Santiago Rodríguez, Burgos, 1938 (dos volúmenes). 
faltó apoyo institucional y gubernamental. Ello condicionó todavía más el retraso y el precario estado de la educación física y su implantación en el sistema educativo, en el sistema militar y su proyección al gran público. Tampoco la poca relevancia de la educación física en el seno de las instituciones científicas, principalmente de la medicina, no ayudó a fijar una literatura médica e higiénica que ofreciese el suficiente crédito científico al ejercicio gimnástico y avalase la seguridad profesional del movimiento gimnástico emergente.

Asimismo, el movimiento gimnástico-deportivo español apenas gozó de un soporte institucional propio de carácter enteramente representativo y estable. La poca presencia y pobre difusión de publicaciones periódicas y especializadas del ámbito profesional, la escasez de congresos y de certámenes propios importantes, la existencia de un pobre asociacionismo y, por ende, las frecuentes disputas de intereses particulares; no ayudaron precisamente a configurar un clima social e institucional adecuado que potenciará la producción y la divulgación editorial de una literatura gimnástico-deportiva propia, abundante y de calidad. Las carencias de obras eruditas y técnicas fueron evidentes siendo necesaria la incorporación de aportaciones extranjeras (Torrebadella, 2011c). La bibliografía foránea, aunque fue poco abundante, ayudó a la erudición documental de los aficionados y profesionales españoles y ofreció obras de gimnástica, de educación física y deportes de calidad. La contribución de la bibliografía extranjera en España ayudó a complementar el déficit de la bibliografía nacional en dos sentidos: amplió el volumen de las obras -sobre todo en el ámbito popular-y cubrió las carencias en el ámbito científico y técnico-pedagógico (Torrebadella, 2009).

Hemos comprobado como las obras fueron presentadas en relación a los acontecimientos de la época y como trataron de abrir su propio espacio en la divulgación y legitimación de la educación física y el deporte. La producción bibliográfica en torno a la educación física y el deporte se desarrolló en ámbitos profesionales concretos, que en ocasiones se yuxtapusieron en espacios e intereses mutuos. Las aportaciones fueron representativas de varios campos profesionales higiénico-medico, militar, pedagógico, de la profesión gimnastica, periodísticodeportivo, etc. -, pero singularmente fueron dirigidas a un ámbito de acción social concreto. Así hemos establecido una clasificación de las obras según el ámbito general descriptivo al que fueron dirigidas:

- Opúsculos propagandísticos dirigidos a fomentar el alcance general de la educación física. (Ámbito divulgativo y propagandístico: ADP, 7 registros)

- Manuales o tratados destinados al ámbito educativo, ya fuesen al servició del docente o de uso del alumno. Además de otras obras pedagógicas de divulgación teórica. (Ámbito pedagógico: AP, 35 registros)

- Tratados o documentos del ámbito higiénico-médico que atienden el ejercicio físico como medio higiénico o terapéutico. (Ámbito higiénicomédico: AHM, 9 registros) 
- Reglamentos y manuales producidos y dirigidos al ámbito militar. (Ámbito militar: AM, 8 registros)

- Tratados o manuales gimnásticos dirigidos popularmente a todo tipo de personas. (Ámbito gimnástico popular: AGP, 14 registros)

- Obras literarias y técnicas dirigidas a la afición deportiva. (Ámbito deportivo: $\mathrm{AD}, 15$ registros)

- Tratados de carácter científico-técnico o de ensayo dirigidos a círculos eruditos y profesionales. (Ámbito científico-técnico: ACT, 9 registros)

- Documentación bibliográfica dirigida a profesionales. (Ámbito bibliográfico y documental: $\mathrm{ABD}, 3$ registros)

\subsection{LAS CONTRIBUCIONES EN EL ÁMBITO DIVULGATIVO Y PROPAGANDÍSTICO}

La Educación Física del Hombre del Dr. Félix González (1814) representa la primera aportación propagandística de la educación física española. En dicho discurso el autor se lamentaba de la decadencia generalizada en la que se encontraba España y en especial la educación física: " $Y$ qué obstruidos por un conjunto de causas politicas todos los caminos del saber, hemos tocado por desgracia hasta término de descuidar la educación física, que es la obra de más consecuencia y trascendental contra la patria, es indudable!" (p. 4). Ante tal situación propuso que el gobierno ilustrado considerase las medidas para trazar un completo plan de educación física que secase a España del doloroso estado en que se encontraba.

Tras un largo período de silencio y de desolación cultural y científica, las aportaciones propagandísticas no tuvieron repercusión hasta la llegada de Francisco Aguilera, conde de Villalobos (1817-1867). La figura de Villalobos y la divulgación de Ojeada sobre la gimnasia, utilidades y ventajas que emanan de esta ciencia (1842) y acerca del establecimiento de un Gimnasio Normal en Madrid (1845), marcaron un punto de inflexión del movimiento gimnasiarca español y sirvieron para iniciar una larga campaña de propaganda a favor de la cultura y regeneración física (Climent, 2001; Piernavieja, 1962). Villalobos pedía que España se pusiera en materia de gimnástica a la altura de las naciones más avanzadas. Con el proyecto acerca de la formación de un Gimnasio Normal en Madrid, extensamente divulgado en la prensa, pretendía elevar la gimnástica al nivel de las ciencias e intentar concienciar al pueblo de su importancia, y advertir de aquellos "perniciosos resultados, que una aplicación de sus reglas puede ocasionar: el descredito que acarrean a la verdadera ciencia charlatanes mercenarios y locuaces, que trafican con la buena fe de sus semejantes" (Villalobos, 1845: 24). 
Otros opúsculos propagandísticos fueron editados por los profesionales de la gimnástica con el objeto de captar usuarios o clientes para sus gimnasios. Una Verdad o consideraciones sobre la utilidad de la gimnástica, del barcelonés Joaquín Ramis (1865), pretendía difundir las ventajas higiénicas y médicas de la materia, que contribuían a solventar aquello que los medicamentos y la medicina común no podían resolver: “... nos hemos propuesto escribir el presente Folleto para trazar, a grandes rasgos, el resultado de nuestras observaciones, poniendo de manifiesto la influencia bienhechora de la Gimnástica, que pudiera muy bien apellidarse Arte regenerador de la especie humana" (p. 3).

Los opúsculos propagandísticos y divulgativos en torno a la gimnastica y el deporte fueron sucediéndose eventualmente a lo largo de los años. Este espació de divulgación también fue ocupado por la Iglesia que en ocasiones puso interés educativo en la gimnástica y el sport. En Cataluña la Iglesia adoctrinó el carácter religioso del deporte y estimuló las prácticas deportivas a través de campeonatos y la creación de las primeras asociaciones del deporte escolar. Una de las voces que se propiciaron fue a cargo del reverendo Félix Sardá Salvany (1814-1916). En 1908 el presbítero sabadellense se ocupó de L'sport católich, primera opinión explicita que sobre el deporte realizó un miembro de la Iglesia en España. Félix Sardá llegó a recomendar la creación de centros deportivos católicos, considerándolos como una parte más de la acción educativa y del apostolado de las parroquias.

Entre todas las aportaciones deseamos destacar la memoria -presentada en los Juegos Florares - del profesor de gimnástica Adolfo Revuelta (1912) que espuso de forma sumamente crítica los argumentos de porqué había que fomentarse la Necesidad e importancia de la educación física. El profesor criticó tanto el sistema educativo y la forma hostil en la que se impartía la gimnástica, como la decadencia física generalizada de la población; sobre todo cuando se comprobaba que oficialmente "la mitad del cupo de reclutas no pesaban 50 Kilos, ni tenían tórax digno de tal nombre, ni estatura, ni circunferencia anatómica, ni nutrición suficiente para ser soldados de combate" (p. 12-13). La aportación de Adolfo Fernández Revuelta refleja la campaña de divulgación y de reivindicación de la educación física que se gestó en el primer tercio del siglo XX.

\subsection{LA CONTRIBUCIÓN EN EL ÁMBITO PEDAGÓGICO}

Las aportaciones bibliográficas de la educación física y el deporte que se generaron desde el ámbito pedagógico o que incidieron en él abarcaron variadas manifestaciones. Generalmente atendieron contendidos de la materia gimnástica en el ámbito escolar, pero también se mostraron preocupaciones por atender las necesidades de una educación integral, completa e higiénicamente saludable, en una concepción de la educación física mucho más amplia. 
A principios del siglo XIX se incorporaron en la bibliografía las primeras obras de educación física escolar redactadas bajo la influencia pedagógica de Pestalozzi y la gimnástica de Guts Muths. Nos referimos a las obras de los franceses Amar y Jauffret, La gimnástica o escuela de la juventud (1807), y la del aragonés Vicente Naharro, Descripción de los juegos de la infancia (1818). La primera tiene especial importancia ya que consideró la gimnástica y los juegos corporales bajo la percepción pedagógica de la educación física moderna $\mathrm{y}$, por tanto, de aplicación en el ámbito escolar. La aportación de Naharro (1818), que seguía la misma orientación pedagógica que la anterior, puede ser considerada como la primera publicación nacional de alcance popular para la enseñanza de la educación física. Además, sus seis páginas para el aprendizaje de lectura que instruían sobre preceptos de convivencia social y moral, junto a los ejercicios físicos, configura la obra como el primer el manual de educación integral escolar. En 1856, todavía seguía siendo considerado como una excelente obra de lectura para las escuelas de Instrucción primaria (Torrebadella, 2011b).

Las reformas educativas a partir de la Ley de primera enseñanza de 1838, marcaron la necesidad de incorporar en la literatura pedagógica obras modernas. Una de estas aportaciones fue la obra de Marco Antonio Jullien (1840), Ensayo general de educación física, moral e intelectual -escrita originalmente en París (1808)- se reveló como un excelente manual pedagógico de educación integral, que situado en la corriente pestalozziana tuvo muy buena acogida. Este tratado, que fue oficialmente reconocido durante varias décadas como manual de estudio para los directores y maestros de enseñanza, legitimó en el ámbito pedagógico el sistema gimnástico de Francisco Amorós. El 10 de septiembre de 1845, el Consejo de Instrucción Pública propuso nuevamente la obra de Jullien, como útil para los profesores y directores de instrucción primaria; hecho que provocó una inmediata segunda edición.

También en el ámbito de la educación familiar o doméstica La gimnástica del bello sexo (1827) acercó el ejercicio corporal a la mujer, aunque con ciertos reparos morales (Gutiérrez, 1994). Sin embargo, destacamos esta singular aportación, puesto que durante el resto de siglo no se escribió, que conozcamos, ninguna otra publicación que cumpliera una finalidad higiénico-práctica para orientar la educación física de la mujer (Torrebadella, 2011a).

El sistema público de educación tanto para la primera como para la segunda enseñanza, no contemplaba para nada una asignatura de educación física o gimnástica. Esta materia solamente fue atendida como clases de adorno en algunos de los colegios privados más elitistas de país (Simón, 1972). Las necesidades del momento hicieron que su publicasen algunos opúsculos gimnásticos como el de Borja Ramírez (1856), Elementos de gimnasia. Esta obra fue el primer manual de gimnástica propiamente dicha dedicado a cubrir la educación física de los alumnos en base al método gimnástico de Amorós. El autor expresaba el deseo que la gimnasia fuese realizada hora al día en todos los Colegios. No se volvió a publicar 
ninguna obra de gimnástica educativa hasta al cabo de doce años. La obra de Joaquín Lladó (1868) Nociones de gimnasia higiénica fue el primer gran tratado pedagógico de educación física que se publicó en España, incorporando, además, un capítulo a la gimnástica del sexo femenino. Contó con una importante divulgación promocionada por el Magisterio de instrucción primaria y la prestigiosa editorial educativa de Julián Bastinos. Dispuso de cuatro ediciones hasta 1912; incluso, sorprende conocer que fue la única obra española traducida a otro idioma, el francés (Llaverías, 1935).

Por toda Europa se imprimían obras de gimnástica. En España, el desierto de esta literatura especializada parecía no preocupar demasiado. Al cabo de diez años del tratado de Lladó, José del Campo (1878) presentaba Elementos de educación física, un método para la enseñanza y práctica de la gimnástica, redactado expresamente para los establecimientos de instrucción. El autor pretendía aportar un manual sencillo de entender y fácil de aplicar en los centros de enseñanza como en las sociedades gimnásticas. José del Campo era conocedor de la falta de un profesorado cualificado para la enseñanza gimnástica, y por ello presentaba una obra que pudiese ser entendida por cualquier otra persona ajena a la especialidad.

Podemos consensuar que la educación física alcanzó el pleno reconocimiento pedagógico con las obras monográficas e intervenciones de Pedro de Alcántara García (1842-1906). Alcántara García (1882) presentó en Teoría y práctica de la educación y la enseñanza, el mayor tratado pedagógico escrito en España. En esta vasta obra compuesta de cinco tomos, el último fue dedicado a tratar extensamente los asuntos $D e$ la educación fisica. Hasta la fecha se carecía de una obra que abordase la educación física desde una perspectiva realmente pedagógica e higiénica de forma profunda y amplia. La visión crítica que Alcántara García imprimió a la educación física hizo dotar a la materia de un alcance erudito y posicionarla como una de las principales necesidades a resolver en el sistema educativo.

Coincidiendo con la proclamación de la primera ley de la educación física española, José Sánchez (1850-1913) incorporó el Tratado de gimnasia pedagógica para uso de las escuelas de primera y segunda enseñanza e institutos (1883). El autor, consideró la obra como la primera publicación que presentaba un método de gimnasia pedagógico para la enseñanza, teniendo en cuenta los adelantos de la materia en las principales naciones de Europa y América (Pastor, 2005b: 157-158). Propuso además, como novedad, una diferenciación metodológica por sexos: " $E l$ plan que hemos propuesto difiere en mucho de los que generalmente se siguen en la actualidad, porque en éstos suele emplearse el mismo sistema para los niños y señoritas que para los adultos" (p. 8). La obra superó la calidad de las obras antecesoras y ofreció un importante avance en la compresión y aplicación de la educación física escolar a partir de la susceptibilidad promulgada por la legislación oficial, la Ley de 1883 por la que se creó la Escuela Central de Profesoras y Profesores de Gimnástica (ECG). 
Todavía sin disponer de una legislación educativa que garantizase la educación física como asignatura en la $1^{\mathrm{a}}$ y $2^{\mathrm{a}}$ enseñanza, Dolores Montaner, maestra de $1^{\mathrm{a}}$ enseñanza, aportó en Gimnasia elemental infantil y escolar (1887), un sencillo manual con objeto de facilitar una guía didáctica para la enseñanza de la gimnasia en las escuelas elementales y de párvulos (Pastor, 2005a: 133-134). Con esta obra Dolores Montaner suplantó la aplicación de la gimnástica del método de Amorós conceptuado como peligroso en la utilización de los aparatos- en las escuelas de párvulos y puso de relieve los ejercicios de gimnasia de sala de Schreber (1861), que recomendó Alcántara García (1882).

La contribución de los representantes de la Institución Libre de Enseñanza (ILE) al proceso de legitimación de la educación física y el deporte español es un hecho fehaciente (López Serra, 1998). El ambiente ideológico y regeneracionista que llevó implícito la educación física de finales del siglo XIX y principios del XX estuvo marcado por el liderazgo o el sello de la ILE.

Mucho tuvo que ver la influencia de la ILE para llagar a la Ley de 9 de marzo de 1883, que creó la Escuela Central de Profesoras y Profesores de Gimnástica (1887), un hito histórico cuyos antecedentes, programas y reglamentos quedaron impresos. A partir de este centro de formación se constituyó el primer colectivo de profesionales, hombres y mujeres, que forjaron el apostolado de la educación física de finales del siglo XIX y principios del $\mathrm{XX}^{54}$.

Adolfo Álvarez Buylla (1850-1927), profesor de la Universidad de Oviedo y miembro ILE, aprovechó el discurso de apertura del curso universitario, para insistir sobre el problema de La Educación Física (1888). El discurso trató críticamente sobre cómo mejorar las condiciones la educación física y moral de las Universidades. Buylla propuso imitar los clubes de sport de las Universidades de Cambrige y Oxford, en donde los juegos corporales disputaban la "perfecta armonía de cuerpo y de espíritu y de mejorar la raza" (p. 13).

El doctor Joaquín Decref (1864-1937) fue uno de los alumnos más aventajados de la ECG y paradójicamente contrario método gimnástico de Amorós, que al fin y al cabo fue el que enarboló la citada escuela. Como profesor de Educación física de la Escuela Central de Maestros, presentó un detallado Programa razonado de la asignatura de Educación Física (1888), contrario en España a las ideas generalmente admitidas. Decref rechazó los modelos gimnásticos dominantes fundamentados en el uso de aparatos trapecio, anillas, paralélelas, escalas, etc.- de excesiva influencia militar y propuso la gimnasia sueca; presentándose como el primer profesor en cambiar la orientación metodológica y técnica de la gimnástica dominante.

En el Congreso Pedagógico de Madrid en 1892 destacó una sección dedicada a la educación de la mujer. Una de las intervenciones fue a cargo del Dr. Ángel

${ }^{54}$ En la Escuela Central de Gimnástica (Madrid, 1887-1892) se titularon oficialmente 71 profesores y 16 profesoras de Gimnástica. 
Pulido (1852-1932). En Educación fisica de la mujer, Pulido (1892) expuso una reflexión sobre la necesidad de atender las reformas de la educación general de las niñas y jóvenes españolas, del mismo modo que se estaba haciendo en Europa; es decir, insistió en la modificación urgente de los programas escolares de las niñas y, sobre todo, el de educación física. Destacamos esta ponencia que, aparte de publicarse separadamente, fue divulgada en la prensa feminista de la época ${ }^{55}$.

El Dr. Alejandro San Martín (1847-1908) exdirector de la suprimida ECG, expuso ante el Claustro de la Universidad Central unas Notas sobre la educación física (1893), con objeto de implantar las reformas necesarias en el modo de organizar la enseñanza universitaria. Mencionado la crisis de la enseñanza superior, la cual consideraba aún en el predominio de la escolástica, proponía la incorporación de la educación física en las Universidades a través de las asociaciones de alumnos. Metodológicamente proponía los juegos corporales, aunque no reprobaba, en absoluto, el modelo gimnástico de Amorós.

El Tratado racional de gimnástica y de los ejercicios y juegos corporales (1893) de José Esteban García Fraguas (1870-1908) defiende y representa las aspiraciones académicas de los primeros profesores oficiales de la educación física por legitimar su propio espacio profesional. En tres volúmenes -entre 1893 y 1896- este Tratado abarcó los diferentes ámbitos en torno a la gimnástica, los ejercicios y juegos corporales (Pastor, 2005b: 165-169). Sin duda alguna, la obra más extensa, profunda e incluso, la más importante que se publicó durante todo el siglo XIX. Fue una obra que, en su conjunto, trató de abarcar los diferentes ámbitos de aplicación de la gimnástica: el educativo, el doméstico o civil, el artístico, el recreativo, el militar y el médico. Además, la erudición académica del autor, los datos historicistas tanto de España como del extranjero, los comentarios personales y las aportaciones críticas, indican la profundidad y el rigor del contenido de la obra. La obra fue una importantísima contribución a la materia, refutando todo lo que hasta la fecha se había escrito y publicado en España.

En esta época la Circular de Eduardo Vincenti, director de Instrucción Pública, sobre "Normas para la enseñanza de la gimnástica y hoja antropométrica" (1894), orientó la doctrina y metodología del sistema de educación física para la Segunda enseñanza. Las orientaciones de esta Circular quedaron reflejadas en los tratados más importantes de la época (López, 1894; Pedregal, 1895; Sanz, 1895) ${ }^{56}$. Así, el Manual de ejercicios gimnásticos: para uso de los Institutos y Escuelas Normales de Salvador López (1894), dedicado a Eduardo Vincenti, incorporaba, como novedad, los juegos al aire libre y los sports, además de un apartado dedicado a las colonias y excursiones escolares. En la obra se observa una tendencia hacía la

${ }^{55}$ PULIDO, A. "Educación física de la mujer". El Álbum Ibero Americano, 1893, 1, 2-4; (Continuación) 1893, 2, 14-16; (Conclusión) 1893, 3, 29-30.

56 Circular, 18/03/1894: "Normas para la enseñanza de la gimnástica y hoja antropométrica”, Gaceta de Madrid, 19/03/1894, por Eduardo Vincenti. 
influencia que estaba ejerciendo el modelo anglosajón de educación física promovido por la ILE (Pastor, 2005b: 159-160). En el tratado de Francisco Pedregal (1852-1904) La educación gimnástica (1895), se aprecia una evolución doctrinal respecto a su anterior tratado, La gimnástica civil y militar (1884). Pedregal dejaba a un lado la gimnástica amorosiana para introducirse en el sistema sueco, más acorde con el doctrinario pedagógico de la educación física escolar (Kyung, 2002). La obra trataba de adecuarse a las adaptaciones curriculares del momento incorporando los juegos corporales (Pastor, 2005b: 1607-161). Para Rufino Blanco (1927) era una de las obras más completas que sobre dicho asunto podía consultarse. El tratado fue declarado de utilidad para las escuelas de primera enseñanza ${ }^{57}$. Con el Manual de gimnástica higiénica y juegos escolares (1895), el erudito profesor Marcelo Sanz (1859-1942) inició una productiva campaña bibliográfica (Marín, 2009), aportando decisión a una sistematización conceptual y técnica de la educación física (Pastor, 2005b: 161-162) ${ }^{58}$.

El siglo XX se inició con la esperanza de legitimar la oficialización de la educación física en la enseñanza. La importancia y trascendencia se manifestó con un incremento de la bibliografía procedente del profesorado de primera, segunda enseñanza y magisterio. Se publicaron manuales de texto para los alumnos y guías docentes para los profesores. Las obras de educación física adoptaron un carácter técnico-pedagógico. El profesorado de educación física se convirtió en el principal productor de la bibliografía de su propio ámbito: Eduardo Utor (1901), Luciano Sampérez (1904), José Estadella (1910), Langlois du Feu (1910), Oses Larumbe (1915), Cartilla Gimnástica Infantil (1924), José Eleizegui (1924), Rodrigo Suárez (1925), Jesús Llorca (1926), Cándida Cadenas (1928), Augusto Condo (1927), M. Casals (1930), Pedro Llobera (1934), Pedro Crespí y Leopoldo Quilez (1937), Villalba (1938).

También existieron algunas tesis doctorales que se ocuparon de la educación física (Torrebadella, 2012). Destacamos al doctor Utor (1901), que proporcionó la única tesis que se centró en la discusión pedagógica de la gimnástica y llegó a proponer un método práctico para la enseñanza primaria.

El Manual de Gimnasia Nacional higiénico-civico-militar (1904) fue escrito por el profesor Luciano Sampérez, con el objeto de atender las múltiples solicitudes de directores de colegios de la provincia de Badajoz. La obra, que versa sobre el método de enseñanza seguido por Sampérez, simboliza el legado de aquel dicho: "cada maestrillo tiene su librillo". Con la presente aportación pretendemos

57 Juan Cambeiro (1997, 118-119) menciona, como situación curiosa, que la R. O. 08/06/1898 declaraba útil la Educación gimnástica de F. Pedregal, después que la R. O. de 05/11/1898, rechazase el uso de los libros de texto. El hecho demuestra, una vez más, las paradojas y contradicciones del sistema educativo.

${ }^{58}$ La segunda edición fue premiada con la medalla de plata en la Exposición aneja al IX Congreso Internacional de Higiene y Demografía en Madrid, abril 1897. 
elogiar a todos aquellas personas que en sus poblaciones fueron los verdaderos "apóstoles" de la educación física. En este sentido, Luciano Sampérez representó en la provincia de Badajoz una meritísima contribución (Rebollo, 2009).

El Congreso de Primera Enseñanza de Barcelona fue uno de los mayores acontecimientos pedagógicos de cuantos se realizaron durante el primer tercio del siglo XX. En cuanto al pensamiento pedagógico sobre la educación física, todas las propuestas aprobadas en el Congreso estaban encaminadas a racionalizar las condiciones higiénicas del ejercicio físico y de los espacios destinados a él. Una de las mejores y más discutidas ponencias fue la del profesor de gimnástica $\mathrm{V}$. Langlois du Feu (1910) que trató el carácter pedagógico de la educación física y sus problemas: La educación física como base y norma de toda pedagogía racional y biológica. La ponencia fue ampliamente aprobada por el Congreso. Destacamos la propuesta que realizó de crear una Facultad de Educación Física en las Universidades de Madrid y Barcelona. La Ponencia fue publicada separadamente de las actas del Congreso.

La Educación Física en las escuelas de primera enseñanza (1910) del doctor José Estadella (1880-1951), profesor de Educación Física del Liceo Escolar de Lleida, puede ser considerada como una de las primeras aportaciones de la educación física para la enseñanza primaria en el contexto de la Escuela Nueva. En referencia explícita a Alcántara García, el Dr. Estadella comentaba que en la educación física "todo está por hacer". Así analizaba los edificios escolares presentando soluciones, higiénicas, racionales y utilitarias al marco escolar infantil.

La educación física en la enseñanza primaria también vino sustentada por los cambios en los planes de estudios de magisterio, sobre todo a partir del Plan Bergamín de 1914, año en el que la educación física fue oficializa genéricamente para todas las Escuelas Normales. Al respecto se publicaron algunos manuales con el objeto de suministrar guías docentes a los profesores encargados de impartir los llamados cursos de "Ejercicios corporales". Asimismo se publicaron manuales de texto para los alumnos normalistas (Pastor, 2005c). Uno de estos manuales fue el Curso teórico y práctico de educación física de Marcelo Sanz y Roberto Escribano (1914), que puede considerarse como el mejor tratado de aplicación a las escuelas normales de su época. El libro contiene aspectos sobre la educación física del niño, la gimnasia educativa del sistema sueco y una amplia exposición de juegos escolares y deportes.

José Oses (1915), maestro de primera enseñanza en Barcelona, presentó Juegos de patio para niños, una recopilación didáctica para la educación física de sesenta juegos corporales. Con esta obra el autor y los editores pretendían recuperar el espacio didáctico de los juegos infantiles y retornar a la educación física el dinamismo recreativo y estimulante que se había perdido con la preferencia ante la gimnasia metódica del sistema sueco.

La educación física del niño de Hans Spitzy (1917), publicado por la prestigiosa Editorial Calleja, representó en España la incorporación del sistema de 
educación física natural austriaco y una de las apuestas más controvertidas de la gimnasia con el cuerpo al desnudo. La publicación tuvo notable éxito y en 1925 se imprimió una nueva edición.

En el período de la Dictadura de Primo de Rivera, el libro de educación física para la enseñanza primaria que adquirió mayor popularidad y también mayores controversias fue la Cartilla Gimnástica Infantil (1924). Esta Cartilla fue impuesta por el Directorio Militar, para servir de guía al maestro en la aplicación de la educación física. El objeto de la Cartilla fue el de unificar la enseñanza según los contenidos y métodos de la Escuela Central de Gimnasia del Ejército de Tierra de Toledo (1919-1936). Doctrinalmente, la Cartilla puso de manifiesto el carácter político, patriótico y católico de la Dictadura militar (Pradillo, 2005a: 142-146). Así se aplicó la Cartilla obligatoriamente, por Real Decreto, hasta los inicios del período Republicano en las Escuelas Nacionales de primera enseñanza y en las sociedades gimnásticas.

José de Eleizegui (1924) en Los juegos en la infancia, una guía médicopedagógica para padres y maestros, presentó un alegato teórico-científico en favor de los juegos corporales, a partir de la necesidad del movimiento y del ejercicio natural del niño, justificando los beneficios del juego corporal como ejercicio físico educativo (Pastor, 2005b: 183-185). La obra de José Eleizegui fue una defensa del juego al aire libre en la educación física, frente a la tendencia generalizada de la aplicación infantil de la gimnástica sueca, que ocupaba el mayor tiempo de la educación física, dejando poco espacio para los juegos corporales: "no me cansaré de repetir que el mejor ejercicio fisico para el niño es el juego" (p. 140).

La Gimnasia educativa sueca del capitán Rodrigo Suárez (1925) puede tenerse en cuenta como el tratado de gimnástica educativa sueca más completo que se publicó en España. La obra fue de ineludible referencia y complemento a otros tratados de gimnástica. Además, puede admitirse que la obra, dirigida a los maestros y a los profesionales de la enseñanza gimnástica, fue considerada como el manual o guía que orientaba la aplicación metódica de la gimnasia educativa que marcaba la Cartilla Gimnástica Infantil.

Las preocupaciones metodológicas en cuanto a la educación física escolar no desaparecieron con la Cartilla. Las instancias pedagógicas insistieron en buscar o al menos estudiar la aplicación de la educación física en otros países con la intención de mejorar la aplicación en España. En este marco se emplaza la aportación de Jesús Llorca (1926), presidente de la Asociación de Maestros de Madrid, pensionado por la Junta para la Ampliación de Estudios e Investigaciones Científicas, con el objeto de estudiar los sistemas de educación física en Bélgica y Francia. La conclusión de este estudio comparado se presentó en la memoria llamada Juegos rítmicos en la escuela, en donde el autor propuso un método de educación física para las escuelas de primera enseñanza.

El capitán Augusto Condo (1927) presentó Gimnasia e hidroterapia en el desarrollo infantil, un manual docente teórico-práctico de educación física para la 
enseñanza primaria, con el objeto de satisfacer las necesidades sociales de las clases proletarias o más desamparadas. Sorprende como singularmente esta obra, escrita y divulgada extensamente plena Dictadura, atacaba al organismo oficial responsable de la educación física, puesto que recriminaba al Gobierno la dejadez por la materia. Resulta paradójico que el capitán Condo estableciese una propuesta pedagógicamente diferente al margen de la oficial, como era la Cartilla Gimnástica Infantil.

Las contradicciones del sistema de educación física en España quedaron evidenciadas ante la falta de un profesorado femenino que se ocupase de la educación física de las niñas. En el Cursillo de Información sobre Educación Física Femenina que para maestras Nacionales de $1^{a}$ enseñanza organizó del 23 al 28 de Marzo de 1927 en Zamora (1928), la Inspectora de primera enseñanza Cándida Cadenas presentó en una conferencia, que trataba el Proyecto para establecer una Escuela o Sección Superior de Educación Física Femenina. Cadenas reclamaba la obligatoriedad, por ley, de la educación física para toda la enseñanza.

El libro de Miquel Casals (1930), Gimnasia, juegos y deportes puede ser considerado como el último libro de consulta docente publicado antes de la II República. La obra propuso un cambio substancial, puesto que acercaba la educación física a un ámbito metodológico recreativo. Casals no se subscribió metodológicamente a ningún sistema de educación física (Pastor, 2005b: 187). No obstante, consideraba que mediante una correcta adaptación metodología de los deportes al niño, éstos deberían configurar "una de las mejores armas para la educación física" (p. 135). Casals se adelantaba así, a la futura iniciación deportiva en edad escolar ${ }^{59}$. La opción única del deporte como medio de educación física fue un posicionamiento muy atrevido. En la educación física, esta obra puede considerarse como la superación de todas las corrientes gimnásticas vistas hasta entonces. Casals sistematizó ningún método de educación física y expuso el predominio natural de una corriente ecléctica. La obra fue un auténtico cambio en el concepto y en la aplicación de la educación física escolar, superando ampliamente la gimnasia educativa dominante en la época.

El espíritu deportivo de las Escuelas Nuevas, es una memoria de Pedro Llobera (1930), que sitúa el deporte como medio de educación física y de educación integral en el contexto del movimiento de renovación pedagógica de las Escuelas Nuevas, poniendo el ejemplo de la escuela Vallparadís de Terrassa.

En plena Guerra Civil, los profesores de educación física de las Islas Baleares tuvieron que someterse a las directrices del fascista italiano conde Rossi. En este contexto de represión militar se publicaron las Normas de educación fisica infantil (1937). El libro se confeccionó en dos partes: "Educación Física", por Pedro

${ }^{59}$ La Cartilla Gimnástica Infantil (1924) consideraba la práctica deportiva del foot-ball, basket-ball y volley-ball en condiciones adaptadas: pelota, campo, tiempo y sin aplicación estricta del reglamento. 
Crespí, y la "Gimnasia educativa infantil" por Leopoldo Quílez. En sí, se trata de una guía pedagógica para los maestros del magisterio, que inspiraba el sentimiento patriótico y la recuperación de los valores tradicionales que posteriormente legitimó el régimen militar de la Dictadura franquista. Así puede considerarse como la primera publicación sobre educación física de la insurrección franquista. Posteriormente en junio de 1938, el Ministro de Educación Nacional Pedro Sainz Rodríguez organizó en Pamplona el Cursillo de Orientaciones Nacionales de Primera Enseñanza, con el objeto de instruir un magisterio bajo los preceptos falangistas y las disposiciones del nuevo sistema educativo. Una de las conferencias fue Nociones teóricas de educación física de Ricardo Villalba (1938), teniente coronel de Infantería y profesor de Escuela Central de Gimnasia de Toledo. Villalba trazó las directrices de la educación física en el régimen franquista. Las generaciones venideras tuvieron que aceptar la gimnástica educativa sueca, los juegos y deportes, la gimnasia rítmica, los campamentos de verano y, además, impregnarse de la educación premilitar y doctrinal mediante la llamada formación del "espíritu nacional".

\subsection{LA CONTRIBUCIÓN EN EL ÁMBITO HIGIÉNICO-MÉDICO}

En el ámbito higiénico-médico se suscitó la preocupación de hacer llegar a la población los preceptos y los hábitos saludables del ejercicio físico sistematizado, mediante un método adecuado y dirigido por un experto. Esta preocupación fue puesta a juicio por algunas de las tesis doctorales leídas en la Facultad de Medicina de la Universidad Central, que singularmente tuvieron como referente la aportación de Antonio Benzo (1853), que trataba sobre la "Necesidad de fomentar la educación física", primera tesis doctoral conocida de la materia. Las tesis que trataron asuntos en torno a la educación física y los ejercicios corporales fueron publicándose de forma intermitente. La última localizada es la del leridano Epifani Bellí (1914), que se propuso dignificar académicamente la educación física con la finalidad de alejarla del empirismo y dotarla de una entidad científica, aparte de exigir que su enseñanza fuese impartida por un médico especialista (Torrebadella, 2012).

A partir del Manual popular de gimnasia de Sala médica e higiénica del Dr. Schreber (1861) se editaron interesantes tratados populares que atendieron el ejercicio corporal terapéutico y preventivo de enfermedades. Singularmente, el manual de Schreber fue la primera aportación médico-terapéutica y la más representativa del siglo XIX. Los editores del Manual conocían perfectamente el éxito de la publicación en Europa y estaban seguros de su aceptación en España, puesto que tampoco existía competencia alguna de obras similares. El Manual del Dr. Schreber estuvo al alcance de gimnasiarcas, médicos y de todo tipo de gentes que necesitaron un uso higiénico o médico de la gimnástica. Sus numerosas ediciones validan esta obra como la de mayor impacto popular de todo el siglo XIX. Schreber influyó en el resto de obras (Busqué, 1865, Carlier, 1867, Alcántara García, 1882). 
El tratado de Sebastián Busqué (1831-1880), Gimnasia higiénica, médica y ortopédica (1865) puede considerarse como la primera aportación española de la gimnástica médica a la aplicación terapéutica (Climent, 2001). Como exponente de la corriente higiénico-médica, Busqué era partidario de introducir el ejercicio físico como medio terapéutico, pero bajo las consideraciones del método de Ling, aún nada conocido en España. Merece importancia la obra de Busqué ya que retomó y recordó las peticiones que en su día realizó el conde de Villalobos, en cuanto a la necesidad de poseer un Gimnasio-modelo protegido por el Gobierno.

Desgraciadamente, la gimnástica médica en España careció de toda fuente bibliográfica nacional y tuvo que buscar auxilio en las fuentes extranjeras. Los sectores médicos españoles lideraron una campaña de propaganda de la educación física dirigida a todos los frentes: educativo, militar, privado y doméstico, deportivo o público.

La conferencia Necesidad e importancia de la educación física que el Dr. Calatraveño (1896) dedicó a la Asociación Nacional de Gimnástica fue una manifestación más que reafirma la campaña a favor de la divulgación y fomento de la educación física. El autor se lamentaba del poco aprecio por la educación física y de sus terribles consecuencias en la infancia, elevando los índices de enfermedad y mortandad, y afectando al detrimento general de la raza.

En el siglo XX unas de los sistemas de gimnástica que rivalizó con el sueco fue el método de gimnasia respiratoria del Dr. Arnulphy (1908). Este método se conoció en España a través de La salud por la respiración, una sencilla obra presentada en el Primer Congreso Nacional Contra la Tuberculosis, celebrado en Zaragoza, del 2 al 6 de octubre de 1908. El Congreso en pleno elogió la obra y decidió redactar una propuesta a su favor, por la que se solicitó al Gobierno, el establecimiento obligatorio de la Gimnasia Respiratoria en todas las escuelas de niños y niñas del Reino. Las peticiones del Congreso fueron aceptadas, mediante la Real Orden de 5 de enero de 1909, declarando la citada obra de utilidad para la Enseñanza primaria. Aparte de la declaración Ministerial, la influencia de la obra de Arnulphy fue indiscutible. La obra trataba un tema apenas conocido en España, que se había difundido considerablemente en Europa entre sanatorios, centros de reposo, hospitales y escuelas. En España el libro de Arnulphy, con sus cinco ediciones, tuvo gran difusión y fueron bastantes los autores que citaron las ventajas de la gimnasia respiratoria, incorporando capítulos y apartados en muchas publicaciones.

Sin duda alguna, Kinesioterapia del Dr. Joaquín Decref (1914) fue la obra médica de mayor envergadura en el campo de la rehabilitación física en España (Climent, 2001). En un esbozo histórico, Decref comentaba el poco interés habido por las técnicas de la gimnástica médica, citando tan sólo la olvidada obra de Sebastián Busqué (1865).

Ante la emergencia de las prácticas deportivas, el Dr. Decref propuso la creación y la Necesidad de organizar e implantar en España los laboratorios de deportes (1919). En este documento Decref trataba de incidir en la necesidad de 
crear y organizar varios centros de medicina deportiva para la formación del médico especialista en esta rama; una propuesta totalmente inédita que se adelantaba a su tiempo.

L'obra de les colònies escolars, banys de mar i semicolònies per als alumnes de les escoles de Barcelona, 1906-1931 (1932) representa el interés que suscitó la educación física en el Ayuntamiento de Barcelona y pone de relieve el despliegue de recursos y la organización en atender las necesidades higiénico-pedagógicas de los escolares más desfavorecidos de la ciudad. El citado documento expone en una memoria el historial de las colonias escolares del Ayuntamiento de Barcelona, de los Baños de Mar y de las Semicolonias, en la que se destacan los resultados sanitarios logrados en estos proyectos.

El Dr. Emilio Moragas y el Dr. José Suriol (1936) incorporaron en la literatura médico-deportiva los primeros trabajos de investigación sobre los accidentes deportivos. Uno se concretó en el fútbol, el deporte de mayor popularidad y el que más riesgos de lesiones entrañaba en aquella época. El estudio fue presentado como comunicación en el IV Congreso Internacional de Médicos Deportivos de Berlín.

\subsection{LA CONTRIBUCIÓN EN EL ÁMBITO MILITAR}

El ámbito militar preocupado en dotar de una fortaleza y resistencia a los soldados, contribuyó a la reivindicación por establecer una educación física nacional e insistió en revitalizar sentimientos patrióticos en una juventud que debía configurarse como la salvaguarda nacional. En este sentido, también se desarrolló el interés por producir una literatura gimnástica en el ámbito de la instrucción militar.

La traducción de José María Aparici del manual de Instrucción para la enseñanza de la gimnástica en los cuerpos de tropas y establecimientos militares (1852), se validó oficialmente como el soporte técnico de la gimnástica militar de la segunda mitad del siglo XIX. Podemos afirmar que este tratado fue la primera aportación de la gimnastica metódica propiamente dicha, que ofreció en España el conocimiento del sistema gimnástico-militar de Francisco Amorós. Como en Francia, la obra gozó de la protección oficial y, en España, también fue recomendada de uso para todos los establecimientos del ejército, incluso en 1885 aún fue declarado como texto oficial en los gimnasios y cuarteles militares ${ }^{60}$.

Ya en el siglo XX, la renovación de la formación gimnástica en el ejército llegó a concretarse con varios Reglamentos que adoptaron el método sueco de educación física con el complemento de los deportes. El Reglamento provisional de gimnasia para infantería del Ministerio de Guerra (1911) fue posible gracias a los trabajos realizados por los capitanes Federico Gómez de Salazar y Federico González Deleito comisionados

${ }^{60}$ Orden de 16 de diciembre de 1885 como "texto para la enseñanza de la gimnasia y natación en los gimnasios que puedan establecerse por las Armas generales". 
para estudiar la gimnástica militar en el Instituto Central de Gimnasia de Estocolmo y en la Escuela francesa de Joinville. Ello marcó que el Reglamento adoptara el sistema de gimnástica sueca, como el mejor método de formación física del soldado. Con la adopción del sistema sueco se dio por cerrado el largo período de influencia gimnástico amorosiana en el ejército. Sin embargo, las críticas al sistema de formación al ejército solicitaban la urgencia de un centro nacional de educación física militar como ya disponían otros países. Estas demandas militares fueron refrendadas con la influencia de la I Guerra Mundial y el método de gimnasia natural del teniente de la Marina francesa George Hebert que fue justificado como idóneo en la preparación física del soldado. Las críticas fueron apaciguadas con la inauguración en Toledo de la Escuela Central de Gimnasia (1919-1936). A partir de la fecha, la estrecha relación entre esta Escuela y la educación física civil española fue inevitable. Véase en particular las Memorias de los cursos de 1920, 1921, 1923 (1924) del citado Centro.

Años más tarde y en pleno apogeo de la gimnástica en el ejército, el nuevo Reglamento de instrucción física para el Ejército (1927) se encargó de apartar el obsoleto Reglamento Provisional. El nuevo Reglamento representó el modelo seguido por la Escuela Central de Gimnasia y tuvo un contenido ecléctico entre la gimnástica sueca, el método natural de Georges Hebert y el modelo deportivo inglés. Fue la constatación teórica y práctica del sistema español de instrucción física militar y educación física. El Reglamento representó la obra cumbre de la educación física en el ejército, dejando atrás las viejas concepciones de la gimnástica para entrar en un nuevo concepto de educación física más adaptado a los tiempos modernos.

La influencia más fehaciente que ejerció el ámbito militar en la educación física española quedó explícita en la Cartilla Gimnástica infantil (1924). Asimismo, los sectores militares contribuyeron a aumentar la escasa bibliografía existente y a la divulgación entre la población civil (Condo, 1927; Suárez, 1925; Trapiella, 1933). Una aportación a la bibliografía deportiva fue auspiciada por la edición de reglamentos deportivos a cargo de la Escuela Central de Gimnasia. Este dato demuestra la relevancia que tuvo la orientación deportiva en la instrucción física militar, así como la contribución en la difusión deportiva que dicha institución protagonizó en el ámbito civil y popular, a través de reglamentos deportivos como el Foot-ball Rugby. Reglamento (1927).

El Curso de información para comandantes del ejército sobre educación fisica, ciudadanía y premilitar fue organizado por la Escuela Central de Gimnasia, por encargo del Comité Nacional de Cultura Física (1929). Dichas instituciones fueron las responsables de organizar un plan de actuación general de educación física y ciudadanía premilitar que, con el nombre Servicio Nacional de Educación Física, Ciudadanía y Premilitar, dirigió el general José Villalba.

El Escultismo de Baden Powell (1857-1941), se inspiró en las doctrinas militaristas y en la naturaleza. En España los Boy Scouts fueron constituidos en la asociación patriótico-pedagógica de los Exploradores de España (1912). La 
asociación fundada por el capitán Teodoro Iradier (1869-1940), dispuso de la colaboración de importantes miembros de la sociedad y el apoyo incondicional de S. M. y la protección en tiempos de la Dictadura. Su expansión en España estuvo especialmente influenciada y dirigida por representantes de la institución militar. En una pedagogía marcadamente paramilitar, los Exploradores de España representaron la continuación de los antiguos batallones escolares y reforzaron el ambiente regeneracionista que reclamaban algunos sectores al servició de los poderes conservadores. Los Estatutos y reglamento interior, provisionales (1912), marcan el inicio de este movimiento de influencia en España.

Otro tipo de obras tuvieron una contextualización en el marco de la guerra civil. En la retaguardia las milicias Republicanas mantuvieron una celosa preocupación en dotar a los reservistas de una óptima preparación físico-militar. Con el citado propósito, Antonio Paso (1938), profesor de la Sociedad Gimnástica Española, editó varias obras. Una fue Cartilla de educación física. Se trataba de un pequeño manual de la 150 Brigada Mixta que pretendía colaborar en la educación física y las aptitudes del soldado.

\subsection{LA CONTRIBUCIÓN EN EL ÁMBITO POPULAR}

La actuación de algunos profesionales de la gimnástica fue remarcable para divulgar obras técnicas de uso privado o doméstico dirigidas generalmente a la población civil. La producción bibliográfica de este colectivo representó un elemento de identidad propia, que generó el impulso necesario para el desarrollo popular. Inicialmente destacamos la poca literatura técnico-gimnástica existente que cubrió este espacio: Fernández Villabrille (1849), Moratones (1863), Pedro Carlier (1867), Salvador López (1873), Francisco Pedregal (1884) o Serrate (1887).

Fernández Villabrille (1849) aportó Gimnástica, una sencilla publicación, en la que trató de divulgar el alcance que la gimnástica estaba protagonizando. Este documento fue la primera información popular que sobre gimnástica recibió el público español. Consistía en un folleto de 16 páginas ilustradas, de una colección de temas varios para la instrucción del pueblo.

Los primeros tratados de gimnástica publicados en España representaron la influencia amorosiana (Hernández, 1988). Uno fue Nociones elementales de gimnasia, para jóvenes de ambos secsos, del barcelonés Antonio Moratones (1863), que representa la primera aportación de gimnástica enteramente práctica, escrita por un profesional de la gimnástica. Anótese que es también el primer tratado cuyo título incide en la gimnástica de ambos sexos.

El Tratado de gimnasia médica y civil de Pedro Carlier (1867) fue considerado por el autor, como el mejor Tratado escrito en España. Incluso consideraba que había adelantado y mejorado la obra de Amorós. Carlier se apropió de una falsa autoridad, ya que presentó un tratado para la gimnástica higiénico-médica de fines profilácticos y terapéuticos sin pertenecer al cuerpo médico. Además, aunque 
plagiara parte importante del manual de Schreber (1861), la intencionalidad médica quedó muy alejada de su objeto No obstante, el valor de este Tratado puede encontrarse en los contenidos relativos a la organización y funcionamiento de los establecimientos gimnásticos, ya que principalmente fue dirigida con la intención de servir de guía útil a los profesores y directores de gimnasios (Pastor, 2005b: 152-154).

El gimnasio de López Gómez (1873) fue la primera obra con la que se dio a conocer este sevillano que inicio una larga y prolifera aportación bibliográfica en la educación física española. Se trataba de un tratado de gimnástica higiénica y civil. Curiosamente el tratado fue puesto a la venta dividido en cuadernos, con previa subscrición $^{61}$.

Francisco Pedregal (1884) presentó Gimnástica civil y militar, un tratado muy bien ilustrado, como la manifestación más representativa del método de Amorós. Pedregal quiso que el tratado fuese tenido en cuenta como texto útil para todos los cuerpos e institutos y academias militares. Aunque causó un considerable impacto, la obra representó el último conato de gimnástica amorosiana y la tendencia gimnástico-pedagógica seguida por la ECG.

El bilbaíno Felipe Serrate (1831-1923) incorporó el tratado gimnástico que aconteció más periplos de toda la bibliografía española. Es conocido que para publicar esta obra el autor tuvo que embargar toda una vida (Vitoria, 1999). La contribución de Serrate a la bibliografía de la educación física fue por partida doble. Por un lado, publicó una revista Ilustración Gimnástica (1886-1887) y, al mismo tiempo, introdujo por capítulos el citado Tratado. Según Serrate, la consumación del proyecto fue destinado a ofrecer "utilidad para todos mis comprofesores, para los colegios y escuelas, y para toda persona privada o particularmente quiera ejercitarse en los ejercicios gimnásticos" (p. 1), uno de sus más ansiados sueños.

Los sistemas gimnásticos de principios de siglo suscitaron un intenso debate doctrinal y técnico. Los enfrentamientos entre unos y otros sistemas gimnásticos lograron confundir al público de la conveniencia de los diferentes tipos de gimnástica. En esta confusión, aparecieron otros sistemas de carácter más individualizado y alternativos a todo cuanto se había dicho. Entre estos sistemas alternativos debemos encajar el Manual de gimnástica higiénico educativa para usar con acierto la Polea Universal del Dr. E. Cleriot (1900). La "polea universal" debe apreciarse como uno de los aparatos gimnásticos más populares de la época, sistema que representaba la concepción más moderna del gimnasio en casa.

En Los ejercicios gimnásticos en el bello sexo de Julián de las Barreras (1903), profesor titulado en la ECG, indicaba el escaso número de profesionales en tratar los temas de la educación física de la mujer. Esta sencilla obra puede ser

${ }^{61}$ Esta obra fue publicitada en los veinte números de la revista Ilustración Gimnástica (1886-1887). 
considerada como la primera gimnástica del siglo XX dirigida exclusivamente al sexo femenino: "En tan lamentable estado de descuido se halla la práctica de ejercicios gimnásticos por la mujer, que es un hecho admitido que nadie se ocupa de pensar en ellos y muchos están lejos de considerarlos como uno de los puntos esenciales en la educación del bello sexo" (Barreras, 1903: 7).

En el primer tercio del siglo XX la aceptación progresiva de la gimnasia sueca como método educativo e higiénico para toda la población fomentó la divulgación de los manuales gimnásticos (Kumlien, 1907; Romero, 1905; Saimbraum, 1912). Estas obras muy populares por su carácter doméstico fueron destinadas a todo el público.

La Cartilla-compendio de gimnasia racional a pie firme y manos libres de Vicente Romero (1905) representó la primera publicación sobre la gimnástica sueca, propiamente dicha, que se publicó en España. El autor proponía uniformar los programas de educación física con la gimnasia sueca y recomendaba el método como reforma para las Sociedades gimnásticas y deportivas, que ya se habían abandonado, únicamente, al ejercicio recreativo del sport.

La versión española de La gimnasia sueca para todos, del sueco L. G. Kumlien (1907) representó la aceptación y la implantación popular del método de gimnasia sueca durante el primer tercio del siglo XX, siendo conocidas, al menos tres ediciones y varias reimpresiones ${ }^{62}$. Posteriormente, la obra de mayor aceptación fue Salud, fuerza y belleza por medio de la gimnasia sueca del Dr. Saimbraum (1912) -Juan Bardina Castara (1877-1950) -, que en su época, podría haberse calificado de Best Sellers, por el considerable número de ediciones y de tiradas que se hicieron. De esta obra se constatan ediciones voluminosas para la época, con tiradas de hasta 10.000 ejemplares. En el período de la II República se publicaron, en varias ediciones, al menos 25.000 ejemplares. Fue la obra más emblemática y popular de su género y la que contribuyó a la inflexión hacia la popularización de la gimnasia sueca en España, y al destierro de la gimnástica de aparatos o de Francisco Amorós.

A partir de 1919 fue determinante la presencia del manual del método de J. P. Muller (1866-1939), Mi sistema. Quince minutos de trabajo diario para la salud (1919). El método de este higienista danés rivalizó con el sistema gimnástico sueco y logró convertirse en el método más popular de la gimnástica cotidiana de tipo domestico. Asimismo, la obra de este danés fue la más popularizada de toda Europa. El sistema de Muller se tradujo a 24 lenguas y para Carl Diem (1966), este "riguroso reformador" de la educación física debe ser venerado como "uno de los más grandes higienistas de nuestro tiempo" (p. 146).

La salud por el ejercicio de J. B. Olavarrieta (1930) corresponde a la única obra popular publicada en España que atendió la gimnástica exclusivamente a

${ }^{62}$ En la actualidad es fácil poder encontrar esta obra en alguna de las librerías anticuarías, lo que supone, que aparte de las ediciones, también hubo una importante impresión del número de ejemplares. 
través del método natural. La obra de Olavarrieta fue novedosa, adelantándose diametralmente a los sistemas gimnásticos empleados en España hasta el momento; se opuso a los valores competitivos del deporte y se situó en el contexto naturista de los años treinta. Es por ello que incorporamos este singular y popular manual, ya que se diferenció de todos cuantos se hubieron escrito hasta la fecha.

Otro excelente tratado fue Ciencia y arte de la educación fisica (1933) del teniente y profesor en la Escuela Central de Gimnasia Francisco Javier Fernández Trapiella. Este tratado representó una de las mayores contribuciones a la divulgación de la educación física en el seno del ejército, pero además, también supuso la excelente aportación de un manual completamente aplicable para el ámbito educativo y doméstico ${ }^{63}$. Como profesor de la Escuela Central de Gimnasia, el autor fue partidario de la utilización del método sueco y, para justificar su utilidad como único método completo de educación física, realizó un importante estudio crítico del resto de métodos conocidos y del llamado problema de la educación física en España.

\subsection{LA CONTRIBUCIÓN EN EL ÁMBITO DEPORTIVO}

En el siglo XX ubicamos en el ámbito deportivo un sector emergente de aficionados y de periodistas deportivos que representó y albergó un nuevo escenario para una bibliografía propia. Las pocas aportaciones de la literatura técnico-deportiva de principios del siglo XX partieron de iniciativas aisladas $\mathrm{y}$, más bien, tuvieron una misión de "apostolado", que de negocio.

La primera aportación en el ámbito deportivo surgió del intento de Marcelo Sanz por crear una fecunda y genuina Biblioteca de Educación Física Nacional. El Cricket, de Peter Barrilero (1900) fue el primer número de la colección de esta Biblioteca y marcaba la influencia que estaban ejerciendo los deportes anglosajones. Al contemplar esta obra, nos encontramos delante del primer proyecto propagandísticos de deporte español: "Al publicar este primer folleto de una serie que, todos juntos reúnan los juegos corporales de mayor utilidad para la educación fisica de la juventud, creemos prestar un pequeño servicio a la higiene y a la pedagogía patria" (Barrilero, 1900: 4). En este sentido, el profesor de educación física Marcelo Sanz comentaba en el prólogo, que "en el extranjero tienen ya hecho el trabajo que nosotros vamos a hacer" (p. 1).

En 1902, el éxito que tuvieron los actos deportivos organizados por las fiestas de la Nuestra Señora de la Merced en Barcelona, indicaban que en el ámbito de la cultura física algo estaba cambiando. Sin duda alguna la Federación Gimnástica Española (FGE) fue la principal institución que asumió el protagonismo de

${ }^{63}$ De esta obra constan, al menos, dos ediciones más de la época franquista, una de 1942 y, otra de 1952, que fueron reeditadas y ampliadas por el autor en respuesta a múltiples solicitudes. 
introducir y extender las prácticas deportivas en España. A principios del siglo XX, la FGE organizó importante festivales y concursos como promoción de los nuevos deportes ${ }^{64}$. Uno fue el formidable programa de concursos que se realizaron bajo los auspicios del Ayuntamiento de Barcelona en las Ferias y Fiestas populares de Ntra. Sra. de las Mercedes los días 24, 27 y 28 de septiembre de 1902. La FGE desplegó una destacada organización en la que fue la primera gran exhibición del deporte español.

El Manual de Sport de Antonio Viada (1903) puede ser considerado como la primera publicación española importante que trataba de ilustrar y propagar los deportes en su acepción moderna. Fue una destacable aportación al conocimiento técnico, en una época que el deporte era muy minoritario: "Todo el trabajo de propaganda deportiva debe reducirse en España a la meritísimas y entusiastas asociaciones aisladas, y a la de no menos meritísimas publicaciones sin resonancia, que más tienen de apostolado que de negocio" (Viada, 1903: 19-20). Puede decirse que fue una pequeña y completa enciclopedia de cuantos sports se practicaban.

Alejandro Barba (1911) presentó Foot Ball, Basse Ball y Lawn Tennis, un pequeño manual de divulgación deportiva publicado en la extraordinaria y voluminosa Biblioteca de "Manuales Soler". Los volúmenes -más de cien- de esta "biblioteca útil y económica de conocimientos enciclopédicos" fueron extensamente difundidos por España y por los países latinoamericanos. Con esta obra se deseaba contribuir a la "vulgarización de los deportes que apenas si han franqueado las divisorias que les separaban de nuestra nacionalidad" (Barba, 1991: 5) y, con ello, coadyuvar a la regeneración de la juventud española con una literatura deportiva nacional.

El madrileño José Fernández Zabala (1913), miembro del Club Alpino Español, publicó Deportes de nieve, considerado como el primer manual técnico de su género. A partir de esta fecha, los deportes de nieve fueron auspiciados como las prácticas deportivas de los grupos excursionistas en la época invernal.

La producción bibliográfica deportiva cedió al especial interés de las editoriales que publicaron "bibliotecas deportivas". Como se conoce, "Los Sports" de la Librería y Editorial Sintes de Barcelona fue la colección más popular de la época. La colección "Los Sports" fue iniciada y dirigida por José Elías Juncosa (18801944) en 1914, representando una valiosa contribución a la expansión y conocimiento popular de las prácticas deportivas (Balius, 1998). Football asociación fue el primer volumen de la colección que escribió Elías (1914). A partir del éxito de este primer número, Elías consiguió agrupar una importante colección con la colaboración de destacados aficionados y "apóstoles" del deporte, que participaron como prologuistas y autores de las obras. Esta vasta colección de 21 volúmenes supuso un osado proyecto de anticipación editorial, puesto que la

${ }^{64}$ En 1898 se constituyó la FGE que agrupó sociedades gimnásticas de todo el territorio nacional. 
práctica deportiva en España era aún minoritaria. Además debe destacarse que la colección fue una visión acertada de futuro que no tuvo que recurrir a los autores y las obras extranjeras. Desde su aparición y durante veinticinco años, la Biblioteca "Los Sports" fue la más popular y la más significativa del deporte español.

El desarrollo deportivo en Cataluña fue excepcional y el asociacionismo deportivo fue acompañado de una comprometida mediatización publicista que descolló en una potente prensa deportiva (Pujadas y Santacana, 1997). El asociacionismo fue impulsado por organizaciones institucionales como la constitución de las primeras federaciones deportivas, el Sindicato de Periodistas Deportivos (1911), el Comité Olímpico Catalán (1914), la Confederación de Federaciones Deportivas (1922), la Mutualidad General Deportiva (1932) o la Academia de Educación Física (1934). Asimismo, el Gobierno catalán manifestó un notable interés por encauzar el movimiento deportivo a través de instituciones como la Ponencia de Educación Física (1922) y el Comisariado de Educación Física y Deportes (1936). En este contexto, el libro deportivo fue un engranaje más que colaboró en la emergencia social del deporte en Cataluña y, por extensión, al resto del Estado.

Destacamos Álbum histórico de las sociedades deportivas de Barcelona de Emilio Navarro (1916), que debe ser considerado como la primera obra historicista del asociacionismo deportivo. En ella se detallan los inicios de las primeras y más representativas asociaciones del deporte barcelonés y un espació biográfico de homenaje a las personalidades más emblemáticas.

En pleno apogeo del deporte popular, algunos de los mejores deportistas de la época escribieron sus memorias y a portaron consejos técnicos. Mis menorías del futbolista Paulino Alcántara (1924) puede representar el éxito mediático, que en el deporte de masas, llegaron a alcanzar algunos de los deportistas de los años veinte. Paulino Alcántara figura indiscutible del FC Barcelona, es considerado como uno de los mejores jugadores de todos los tiempos.

En Cataluña se llegaron a publicar obras de gran calibre. En torno al Fútbol Club Barcelona se destacó la voluminosa obra, compendio histórico, publicada por el redactor deportivo Daniel Carbó (1924) con motivo de las "bodas de plata" del club barcelonés. En este colosal tratado histórico se destaca la pionera contribución del FC Barcelona al deporte.

En relación con el movimiento Olímpico, hemos de destacar la Memoria liquidación y balance de la participación de España en los Juegos de la VIII ${ }^{a}$ Olimpíada. Cuadro general de clasificación de resultados, quizás porque nos encontramos ante el primer documento oficial publicado y divulgado por el Comité Olímpico Español (1925). En la VIII ${ }^{a}$ Olimpiada de París (1924) el Comité Olímpico Español desplegó un total de trece deportes, de los dieciocho previstos: Atletismo, remo, natación, water-polo, esgrima, tenis, boxeo, hípica, pelota vasca, lucha greco-romana, yachting, fútbol y polo a caballo.

Para representar el alto grado de madurez asociativo que adquirió el deporte catalán en la segunda década del siglo XX en relación al resto de España, 
presentamos como documento destacado los Estatutos de la Confederación Deportiva de Cataluña (1927). La entidad contaba con veinticinco representaciones del asociacionismo deportivo entre las que se destacaban once federaciones deportivas regionales.

Destacamos el Manual d'excursionisme (1927) de José Ma Batista Roca (18951978), como el alegato más representativo del movimiento juvenil excursionista nacional catalanista: “L'Excursionisme és l'esport a què el nostre poble per tradició i per naturalesa sent major afició, el més antic i el més important de tots els que hom pràctica entre nosaltres" (p. 5).

Otra gran obra fue el Llibre d'or del futbol català (1929), que bajo la organización general de B. Ribes Balcells, contó con la colaboración de las plumas más prestigiosas del periodismo deportivo: Narciso Marferrer, Miguel Cabeza, Guardiola Cardellach, J. M. Mateos, Álvaro Presta, M. de Castro, Jacinto Miquelarena o Isidro Corbinos. Puede admitirse que esta completísima obra, compendio histórico del asociacionismo futbolístico catalán, representó el momento álgido al que llegó este deporte a finales de los años veinte. En sí, el Llibre d'or del futbol català representó un homenaje histórico a todas aquellas entidades deportivas y personas que, en particular, hicieron del fútbol el deporte más popular. Es una lujosa obra muy bien ilustrada y con numerosísimas fotografías que se caracteriza por su redacción bilingüe: catalán-español y algunos fragmentos reproducidos al inglés y al francés. Es una joya para bibliófilos.

Durante la II República, el Basquetbol de Joan Bucheli (1938), aparte de ser la primera publicación técnica sobre el baloncesto, tiene la particularidad de tratarse de la primera publicación deportiva publicada por un estamento gubernamental propio del deporte como fue el Comissariat d'Educació Física i Esports de la Generalitat de Catalunya. Sorprende que la obra fuese publicada en plena Guerra Civil, hecho que demuestra la intención de la Generalitat en no renunciar a la divulgación deportiva durante la contienda bélica.

\subsection{APORTACIONES CIENTÍFICO-TÉCNICAS}

En la bibliografía gimnástico-deportiva de la educación física, el carácter erudito en obras de contenido analítico, de ensayo o científico fue raramente prodigado. Sin embargo, podemos destacar aportaciones que, excepcionalmente, ilustraron el campo epistemológico de la materia.

Salvador López (1881) también se ocupó de aludir aspectos sobre la historia de la gimnástica. Así en la Breve reseña histórica de la gimnástica en Europa, el sevillano resumió y sintetizó todo un período de desarrollo en la difusión de la gimnástica moderna. El autor, que se declaró en la portada de esta obra como el "iniciador del proyecto oficial de la Gimnasia en España", estudió y dejó constancia del desarrollo histórico de la gimnástica europea y española, por lo que confiere a la obra la posición de ser la primera aportación comparada de la gimnástica española. 
Por ello destacamos el valioso trabajo documental y crítico sobre el proceso institucional de la gimnástica en Alemania, Suecia, Francia, Italia y España.

Philipe Tissié (1852-1935), médico, psicólogo y profesor en la Universidad de Burdeos, fue considerado como el principal introductor de la gimnástica sueca en Francia. Su influencia en España fue percibida como una de las personalidades más doctas en la materia. Fue muy citado y sus ideas fueron parafraseadas frecuentemente. La fatiga y el adiestramiento físico (1899) fue la principal obra publicada en España. El tema principal está centrado en la investigación y el estudio de las causas de la fatiga física, así como en la aplicación correcta y educativa de los métodos de gimnástica. La obra de Tissié aportó las primeras interpretaciones hacia el acondicionamiento físico y entrenamiento deportivo.

Tuvieron una especial trascendencia las conferencias realizadas en las Asambleas Generales de la FGE: la 1ª ${ }^{\text {a }}$, de 1899 en Madrid; la 2a , de 1900 en Barcelona; y la 3 , de 1901 en Zaragoza. En estas Asambleas, aparte de las discusiones estatutarias y reglamentarias, se debatieron los temas más candentes de la educación física, sobre todo de aquellos que hacían referencia a la organización oficial de la enseñanza de la gimnástica y sus cuestiones metodológicas y pedagógicas. Las Asambleas de la FGE fueron un importante punto de encuentro de todas aquellas personas y entidades gimnásticas preocupadas por resolver los problemas de la educación física. Destacamos las memorias de la Asamblea de Zaragoza (1902) y las ponencias que fueron presentadas por las personalidades más relevantes del momento.

Marcelo Sanz (1913) presentó el Ensayo de una higiene deportiva o los deportes ante la higiene, obra dedicada al que fue primer presidente del COE, el marqués de Villamejor, conde de Mejora del Campo. Fue la primera obra dedicada al análisis del deporte desde una perspectiva crítica de la educación física. Sanz escribió la obra preocupado por el incremento de de las prácticas deportivas sin apenas bases higiénicas. Sanz expuso las tesis que posteriormente, a partir de los años veinte, secundaron la oposición al modelo deportivo, que rechazaron al deporte como único medio para atender la educación física. En este sentido, el profesor Sanz se adelantó al polémico debate que originó la obra del francés Georges Hebert (1925) en El sport contra la educación física.

Hebert (1925) despertó el debate doctrinal que enfrentó al deporte contra la educación física. La citada obra trataba sobre las tendencias del sport y los abusos y contradicciones éticas, morales y sociales que su práctica suscitaba. Hebert advertía de los peligros del sport y disponía los medios para evitar que esta nueva tendencia desnaturalizase la educación física. La obra representó en España, como en toda Europa, el debate doctrinal más rico, genuino, trascendental y de mayor impacto crítico contra el modelo deportivo.

La influencia de Hebert quedó marcada en el libro de Pedro Rico, El "sport" en España, amateurs y profesionales: Educación, distracción, espectáculo (1930). En este ensayo, muy valioso para contextualizar la opinión de la crítica deportiva 
de la época, Pedro Rico llegó a decir que no había deporte, sino todo lo contrario, una anarquía de intereses que desnaturalizaban su verdadero sentido. Citaba que el deporte se había convertido en inmoral, debido a la excesiva valoración por la competición y del espectáculo profesional, afirmando que donde "llega el profesionalismo precisamente moría el sport" (p. 116).

Joaquín Soto (1930) en Historia del fútbol en España dejó importantes datos históricos y estadísticos del fútbol del momento. La obra tiene importancia porque fue la primera aportación que trató conferir una erudita historia popular del fútbol nacional, al alcance de todos.

Un excelente libro fue La mujer y el deporte del Dr. Mollá (1931), primera obra monográfica sobre el análisis del deporte femenino en España. En él se incorporó un interesante análisis crítico en torno al debate que suscitaba la presencia femenina en el deporte, poniendo en tela de juicio el rechazo social mayoritario.

En Cataluña, puede apreciarse al Dr. Juan Soler (1877-1951), como la personalidad de mayor prestigio político y académico de la educación física en el período de la II República. En plena Guerra Civil y siendo presidente del Comisariado de Educación Física y Deportes de la Generalitat y director del Instituto de Educación Física de Cataluña, abordó la ambiciosa redacción del Assaig d'un Pla General d'Educació Física (1936). Se trata del primer volumen de una obra inacabada debido a las preocupaciones de la Guerra Civil. No obstante, permítasenos sugerir, que la obra completa habría sido un manual para formar a los jóvenes del Instituto de Educación Física de Cataluña. Esta obra marcó una inflexión científica y conceptual. El Dr. Soler, aparte del rigor académico deslumbra por un complejo tratamiento de las ciencias aplicadas a la educación física. Puede admitirse que este trabajo representa el alto grado de expresión académica y doctrinal de los representantes catalanes (Torrebadella, 2000b).

\subsection{LAS CONTRIBUCIONES BIBLIOGRÁFICAS DE LA ÉPOCA}

Las aportaciones del Museo Pedagógico Nacional (1915), Bibliografía y material de enseñanza: Educación física - Higiene escolar, de Rufino Blanco (1927), Bibliografía General de la Educación Física y de Amadeo Llaverías (1935) en Catálogo del Gimnasio de Colón (1935) representan una base documental excepcional. Estas obras recopilaron las descripciones bibliográficas contemporáneas de su época, una valiosa contribución que revela el interés por legitimar en el ámbito cultural y académico el corpus doctrinal de la educación física. Estos repertorios bibliográficos se adelantaron a su tiempo y sentaron los cimientos para obtener la infraestructura que permite comprender y alcanzar la omnisciencia necesaria para el desarrollo conceptual y procedimental de la educación física. En la actualidad representan un valor testimonial de primer orden 
para el estudio del legado histórico y bibliográfico de la educación física y el deporte en España.

\section{CONCLUSIONES}

Los cien libros que presentamos son una selección del desarrollo de la educación física y el deporte, y corresponden a una muestra relevante del debate doctrinal y técnico que suscitó la llamada "guerra de métodos" del siglo XIX y primer tercio del siglo XX en España.

Al principio advertimos la influencia y omnipresencia del método de educación física-gimnástica y moral de Francisco Amorós, pero conforme crecía la centuria fue perdiendo paulatinamente su presencia hegemónica por la presencia $\mathrm{y}$ rivalidad con otros métodos, hasta desaparecer a principios del siglo XX. La gimnasia de sala que propagó el doctor Schreber (1861) fue concebida como un método gimnástico higiénico-médico que coexistió con el método de Amorós y logró una mayor popularización de la gimnástica. Luego vinieron otras propuestas pedagógicas que antepusieron el valor higiénico y educativo de los juegos corporales al aire libre como el mejor método de educación física para la infancia y la juventud, cuestionando el rígido sistema amorosiano. Hacia finales del siglo XIX el método de Francisco Amorós fue puesto en duda, perdiendo la confianza de pedagogos e higienistas que vieron mejores ventajas en los juegos corporales al aire libre -de tradición española y otros de origen anglosajón: el sport- y en las bases doctrinales y científicas de la gimnasia sueca, método de educación física que se introdujo en España a través de la influyente bibliografía francesa.

A partir del siglo XX, la emergencia de los juegos corporales al aire libre de influencia anglosajona -el llamado sport- fue ganando terreno a las prácticas gimnásticas, todo ello conllevó una evolución que transitó de la práctica del sport aristocrático a las primigenias prácticas del deporte moderno y después al deporte popular de masas. Paralelamente a este desarrollo deportivo, la educación física también se vio enriquecida con la creciente popularización de la gimnasia sueca que se manifestó idónea para todos los segmentos de población y fue impulsada en el ámbito escolar, militar, familiar y deportivo. En el ámbito deportivo, la gimnasia sueca fue concebida como requisito previo y complementario para la práctica y preparación a los deportes.

A continuación, presentamos a los diversos autores de este período con las citadas aportaciones bibliográficas que contribuyeron a la legitimación social e institucional de la educación física y el deporte en España. Los agrupamos en torno a los distintos ámbitos profesionales a que pertenecían y por orden cronológico:

La aportación de la profesión médica (González, 1814; Benzo, 1853; Busqué, 1865; Decref, 1888, 1914 y 1919; Pulido, 1892; San Martín, 1893; Fraguas 1893; Calatraveño, 1896; Utor, 1901; Cleriot, 1900; Estadella, 1910; Bellí, 1914; Eleizegui, 1924; Molla, 1931, Moragas, 1936; Soler, 1936). 
La aportación de maestros y maestras de primera enseñanza (Naharro, 1818; Fernández Villabrille, 1849; Ramírez, 1856; Lladó, 1868; Alcántara García, 1882; Montaner, 1887; Buylla, 1888; Oses, 1916; Llorca, 1926; Blanco, 1927; Cadenas, 1928, Casals, 1930; Llobera, 1934; Crespi y Quilez, 1937).

La aportación de militares (Aparici, 1852; Pedregal, 1884; Suárez, 1925; Condo, 1927; F. Trapiella, 1933; Villalba, 1938).

La aportación de profesionales de la gimnástica y la educación física (Villalobos, 1842 y 1845; Moratones, 1863; Ramis, 1865; Carlier, 1867; López, 1873, 1881 y 1894; Campo, 1878; Sánchez, 1883; Serrate, 1887; Sanz, 1895 y 1914; Barreras, 1903; Sampérez, 1904; Romero, 1905; Paso, 1938).

La aportación de publicistas y aficionados al deporte (Barrilero, 1900; Viada, 1903; F. Zabala, 1913; Elías, 1914; Navarro, 1916; Alcántara, 1924; Carbó, 1924; Batista Roca, 1927; Soto, 1930; Rico, 1930; Bucheli, 1938).

La aportación de obras extranjeras (Amar y Jauffret, 1807; Jullien, 1840, Schreber, 1861; Tissié, 1899; Kumlien, 1907; Spitzy, 1917; Muller, 1919).

La aportación institucional (Escuela Central de Gimnástica, 1887; Federación Gimnástica Española, 1902; Exploradores de España, 1912; Ministerio de la Guerra, 1911 y 1924; Museo Pedagógico Nacional, 1915; Escuela Central de Gimnasia, 1924; Comité Olímpico Español, 1924; Confederación Deportiva de Cataluña, 1927; Comité Nacional de Cultura Física, 1929).

Con los datos obtenidos, y después de evaluar cada obra en función del número de criterios cumplidos y efectuar una valoración interpretativa, podemos destacar las obras de gimnástica y/o educación física pertenecientes a autores españoles más relevantes en este período: Ojeada sobre la jimnasia (1842) del conde Villalobos, Nociones de gimnasia higiénica aplicables a las escuelas de instrucción de uno y otro sexo como elemento de educación física (1868) de Joaquín Lladó, De la educación física en teoría y práctica de la educación y la enseñanza -tomo V- (1882) de Pedro de Alcántara García, Tratado racional de gimnástica y de los ejercicios corporales (1893) de José Esteban García Fraguas, Salud, fuerza y belleza por medio de la gimnasia sueca (1912) del Dr. Saimbraum (pseudónimo de Juan Bardina) y Bibliografia general de la educación fisica (1927) de Rufino Blanco.

Entre las obras extranjeras traducidas y editadas en España en el ámbito de la gimnasia y/o educación física destacan por su notable influencia: La gimnástica $o$ escuela de la juventud, tratado elemental de juegos, de ejercicios considerados en razón de su utilidad fisica y moral (1807) de A. Amar Duriver y L. F. Jauffret, Manual popular de gimnasia de sala médica e higiénica (1861) de D. G. M. Schreber, la obra de este ámbito más leída del siglo XIX, La gimnasia para todos (1907) de L. G. Kumlien, Mi sistema. Quince minutos de trabajo diario para la salud (1919) de J. P. Muller o El sport contra la educación fisica (1925) de G. Hebert.

Los libros editados sobre el deporte en nuestro país más influyentes fueron los siguientes: Manual del sport (1903) de Antonio Viada, Football asociación (1914) 
de José Elías Juncosa y El "sport” en España, amateurs y profesionales (1930) de Pedro Rico.

Finalmente, podemos establecer que el repertorio de las cien obras que consideramos más importantes y representativas de la bibliografía de la educación física y el deporte entre 1807 y 1938 contribuyó a legitimar de manera decisiva el proceso de institucionalización de la educación física y el deporte en España.

\section{REFERENCIAS BIBLIOGRÁFICAS}

BALIUS JULI, R. "La biblioteca los sports". Apunts d'Educació Física i Esports, 1998, 52, 109-113.

BETANCOR, M. A y VILANOU, C.: Historia de la educación física y el deporte a través de los textos. Barcelona: UPGC - PPU, S.A, 1995.

CAMBEIRO MARTÍNEZ, J. A.: El proceso de institucionalización de la educación fisica en la España contemporánea. Barcelona: Departamento de Teoría y Historia de la Educación, Universidad de Barcelona, 1997 [tesis doctoral]

CLIMENT BARBERÁ, J. M.: Historia de la rehabilitación médica. De la física terapéutica a la reeducación de inválidos. Barcelona: Edika Med, 2001.

DIEM, Carl: Historia de los deportes -vol. II-. Barcelona: Luis de Caralt, 1966.

GUTIÉRREZ RODILLA, B. M.: "La gimnástica del bello sexo. Una avanzadilla de la introducción de higiene en español". En Actas del XXXIII Congreso Internacional de Historia de la Medicina. Sevilla: Sociedad Española de Historia de la Medicina, 1994, pp. 1039-1049.

HERNÁNDEZ VÁZQUEZ, J. L.: "Los aparatos de Amorós y su influencia en la gimnástica española del siglo XIX”. En Seminario Francisco Amorós. Su obra entre dos culturas. Madrid: Instituto Nacional de Educación Física de Madrid, 1988, pp. 31-63.

KYUNG HYUN, K.: La educación física en el siglo XIX español: Análisis de la Educación Gimnástica, de Francisco Pedregal. Facultad de Filosofía y Letras de la Universidad de León, 2002 [tesis doctoral no publicada]

LÓPEZ SERRA, F.: Historia de la educación física de 1876 a 1898. La Institución Libre de Enseñanza. Madrid: Ed. Gymnos, 1998.

MARÍN GARCÍA, E.: D. Marcelo Santos Sanz Romo, iniciador y propagandista de la educación física española: vida y obra. Universidad de Alcalá, Departamento de Didáctica, 2009 [tesis doctoral no publicada]

OLIVERA BETRÁN, J. "Reflexions sobre l'origen de l'esport". Apunts Educació Fisica i Esports, 1993, 33, 12-23.

OLIVERA BETRÁN, J. y OLIVERA BETRÁN, A.: "De les escoles gimnàstiques a la educació física moderna (finals del segle XVIII a finals del segle XX)". En Aplicacions i Fonaments de les Activitats Físico-esportives, Congrés de les 
Ciències de l'Esport, L'Educació Física i la Recreació de l'INEFC-Lleida, Lleida: INEFC, 1994, pp. 231-241.

PALAU DULCET, A.: Manual del libreo Hispano-Americano. Bibliografía general española e hispanoamericana. Barcelona: Lib. Anticuaria de A. Palau, 1948-1977.

PASTOR PRADILLO, José Luis: La educación física en España: fuentes y bibliografía básicas. Alcalá de Henares: Universidad de Alcalá, 1995.

PASTOR PRADILLO, José Luis: "Perspectiva histórica del material escrito de educación física desde el siglo XIX". En ARRANZ, L. (coord.) El Libro de texto y materiales didácticos. Actas del $5^{\circ}$ Congreso sobre el libro de texto y materiales didácticos, $t$. I. Madrid: Universidad complutense de Madrid, 1997a, pp. 343-353.

PASTOR PRADILLO, José Luis: El espacio profesional de la educación Física en España: génesis y formación (1883-1961). Alcalá de Henares: Universidad de Alcalá de Henares, 1997b.

PASTOR PRADILLO, José Luis: Gimnástica. De la inopia conceptual a la utopía metodológica. Madrid: Librerías Deportivas Esteban Sanz, 2003.

PASTOR PRADILLO, José Luis: Educación fisica y currículum. Historia de una asignatura a través de sus programas (1883-1978). Madrid: Editorial PAM., S. L., 2005.

PASTOR PRADILLO, José Luis: Educación fisica y libros de texto en la enseñanza primaria (1883-1978). Madrid: Editorial Dykinson, S.L., 2005a.

PASTOR PRADILLO, José Luis: Manuales escolares y libros de texto de educación física en la enseñanza secundaria (1883-1978). Madrid: Editorial Dykinson, S. L., 2005b.

PASTOR PRADILLO, José Luis: Manuales escolares y libros de texto de educación fisica en la enseñanza en los estudios de Magisterio (1883-1978). Alcalá de Henares: Editorial Universidad de Alcalá de Henares, 2005c.

PIERNAVIEJA DEL POZO, M. “Antecedentes histórico legales de la Educación Física en España”, Rev. Citius, Altius, Fortius. Madrid, 1962, t. IV, 5-150.

PIERNAVIEJA DEL POZO, M. “Antecedentes histórico legales de la Educación Fisica en España". Citius, Altius, Fortius, 1962, t. IV, 5-150.

PUJADAS, X. i SANTACANA, C.: L'esport és noticia. Història de la premsa esportiva a Catalunya (1880-1992). Barcelona: Col-legi de Periodistes de Catalunya, 1997.

REBOLLO SÁNCHEZ, A. "Notas para la historia del Gran Gimnasio de Badajoz (1868-1936)". Revista de Estudios Extremeños, 2009, 2, 865-932.

SÁNCHEZ Y GONZÁLEZ DE SOMOANO, J.: Propaganda gimnástica. Tip. de Alfredo Alonso, Madrid, 1884.

SIMÓN PALMER, M. del C.: La enseñanza privada seglar de grado medio en Madrid (1820-1868). Madrid: Instituto de Estudios Madrileños, 1972. 
TORREBADELLA FLIX, X. "Aproximació a una història de l'activitat física i l'esport mitjançant l'anàlisi de les fonts bibliogràfiques (1800-1939)". Apunts Educació Física i Esports, 2000a, 59, 11-20.

TORREBADELLA FLIX, X.: L'esport català durant la Segona República: el Comissariat d'Educació Física i Esports de la Generalitat de Catalunya. Barcelona: Col-legi de Llicenciats en educació Física i Ciències de l'Activitat Física i de l'Esport de Catalunya, 2000b.

TORREBADELLA FLIX, X.: Contribución a la historia de la educación física en España. Estudio bio-bibliográfico en torno a la educación física y el deporte (1800-1939). Universitat de Lleida, Departament d'Història de l'Art i Història Social, 2009 [Tesis doctoral no publicada]

TORREBADELLA FLIX, X. "La educación física y la actividad gimnásticodeportiva de las mujeres a partir de la bibliografía especializada del siglo XIX". Arenal, 2011, 18, 147-179.

TORREBADELLA FLIX, X. "Vicente Naharro y los juegos corporales en la educación física española de la primera mitad del siglo XIX". Agora para la Educación fisica, 2011a, 13, 165-182.

TORREBADELLA FLIX, X.: Repertorio bibliográfico inédito de la educación fisica y el deporte en España (1800-1939). Madrid: Fundación Universitaria Española, 2011b.

TORREBADELLA FLIX, X. "Las primeras tesis doctorales de la educación física en el espacio científico y profesional sobre la medicina española". Pecia Complutense, 2012, 16, 58-88.

VITORIA, M.: Felipe Serrate. La Ilustración Gimnástica. Madrid: Dirección General de Deportes de la Comunidad de Madrid, 1999 [Introducción a cargo de Manuel Vitoria] 